\title{
Application of levitation-jet synthesized nickel-based nanoparticles for gas sensing
}

\author{
Paula Tarttelin Hernández ${ }^{\mathrm{a}}$, Maxim V. Kuznetsov ${ }^{\mathrm{b}, *}$, Iurii G. Morozov ${ }^{\mathrm{c}}$, Ivan P. Parkin ${ }^{\mathrm{d}}$ \\ ${ }^{a}$ School of Life Sciences, Alison Gingell Building, Coventry University, Coventry CV1 5FB, UK \\ ${ }^{\mathrm{b}}$ All-Russian Research Institute on Problems of Civil Defence and Emergencies of Emergency Control Ministry of Russia (EMERCOM), Davydkovskaya Street 7, Moscow \\ 121352, Russia \\ ${ }^{\mathrm{c}}$ Institute of Structural Macrokinetics and Materials Science Russian Academy of Sciences, Academician Osipyan Street 8, Chernogolovka, Moscow Region 142432, Russia \\ ${ }^{\mathrm{d}}$ Department of Chemistry, Materials Research Centre, University College London, 20 Gordon Street, London WC1H OAJ, United Kingdom
}

A R T I C L E I N F O

\section{Keywords:}

Nickel oxide

Nickel ferrite

Nanoparticles

Gas-sensing properties

Detection

Environmental monitoring

\begin{abstract}
A B S T R A C T
The gas sensing properties of nickel ferrite $\left(\mathrm{NiFe}_{2} \mathrm{O}_{4}\right)$ and nickel oxide (NiO) nanoparticles prepared by a levitation-jet synthesis (LJS) method are reported. These have been compared to the gas sensing properties of a NiO sensor, prepared using a commercially-sourced powder. The microstructure, surface area, particle size and morphology varied widely across the sensors fabricated. Gases included ethanol, acetone, carbon monoxide, toluene and nitrogen dioxide and the gas response of the sensors was investigated at different operating temperatures. The $\mathrm{NiFe}_{2} \mathrm{O}_{4}$ sensor presented most promise as a gas sensor, with outstanding sensor sensitivity towards ppb concentrations of $\mathrm{NO}_{2}$. This sensor was also remarkably sensitive to ethanol and, to a greater or lesser degree, towards acetone and toluene gases. In general, sensors were poorly responsive to the carbon monoxide concentrations tested. This study is one of the first reports of using LJS-based powders for gas sensing applications for the detection of environmentally-relevant gases.
\end{abstract}

\section{Introduction}

In past decades, the fascinating and unique properties of nanostructured materials, together with their versatility for a wide range of applications have granted them steadily growing attention [1]. Among the various nanomaterials that have been studied, metal oxide semiconductors (MOS) have attracted increasing technological and industrial interest due to their properties, some of which include optical, magnetic, electrical, catalytic and gas-sensing properties. These are associated with characteristics such as mechanical hardness, thermal stability or chemical passivity [2].

MOS gas sensors have been the subject of intense research, finding applicability in industrial process monitoring and control, and in environmental and indoor air quality measurements [3]. New technological advances have enabled a better control of the particle size, morphology, surface area, architecture, and electrical properties of metal oxides [4] which, in turn, have resulted in great enhancements in sensor performance [5]. Industrial and domestic activities call for reliable and accurate gas detection systems, especially in relation to the associated concerns with environmental pollution that stem from them [3]. Solid-state metal oxide semiconductor gas sensors have been implemented for a range of commercial applications, but their greatest limitation is a result of their poor selectivity to gases when used in the bulk state [6]. Various methods, including temperature control and addition of surface additives or filtering layers, may be used to improve sensor selectivity [7]. One of the most effective ways in this direction goes through the nanoscale [8].

Simple transition metal oxides are very interesting examples of gas sensing materials. They can be prepared using a number of techniques, such as ultrasonic spray pyrolysis [9], liquid-control-precipitation [10], chemical vapour deposition [11], electrodeposition [12], the sol-gel route [13], through the reduction of metallic salts followed by the oxidation of metallic species [14], pulsed laser ablation [15], and so on. Among such oxides, NiO nanoparticles exhibit multi-functional properties, suitable for a variety of applications including catalysis, electrochromic windows, battery cathodes and sensors $[16,17]$.

Nickel oxide (NiO) and ferrites such as $\mathrm{NiFe}_{2} \mathrm{O}_{4}$, have recently surfaced as novel sensitive materials for the detection of both reducing and oxidising gases that are important from environmental, safety and medical perspectives [18-20]. $\mathrm{NiFe}_{2} \mathrm{O}_{4}$ is an inverse spinel, in which the tetrahedral sites are occupied by $\mathrm{Fe}^{3+}$ ions and the octahedral sites by $\mathrm{Fe}^{3+}$ and $\mathrm{Ni}^{2+}$ ions [21]. This material is widely used in electric and

\footnotetext{
* Corresponding author.

E-mail address: maxim1968@mail.ru (M.V. Kuznetsov).
} 
electronic devices as a magnetic material, and is also applied to the fields of catalysis and gas sensors due to its semiconducting properties [22]. Recently, much attention has been devoted to the controlled preparation of nanosized ferrites because the cation distribution and the resulting magnetic properties are found to be different when compared to those of the bulk counterparts [8,23]. Meanwhile, this material has been confirmed as a good gas-sensing material [24], and its sensitivity is strongly correlated to its crystalline size [25].

Multiple methodologies have been developed to synthesise nanosized $\mathrm{NiFe}_{2} \mathrm{O}_{4}$, some of which include co-precipitation [26], the sol-gel method [27], and the shock-wave [28], mechanical-alloying and pulsed-wire discharge methods [29]. However, there are no facile methods for the synthesis of nanocrystal $\mathrm{NiFe}_{2} \mathrm{O}_{4}$, which is difficult or inconvenient to obtain through multi-step syntheses methods. As such, a cost-effective and scalable technique able to synthesise and control the size and shape of Ni-based nanoparticles is needed [30].

The levitation-jet synthesis (LJS) method is an attractive technique that facilitates the simultaneous control of nanoparticle shapes and sizes [23,31-32]. It is a one-pot, fully-regulated process that does not require additional surfactants or capping agents. This, in turn, serves to minimise the number of precursors utilised and makes mass production of highly pure materials feasible [23].

In the present work, $\mathrm{Ni} / \mathrm{NiO}$ and $\mathrm{NiFe}_{2} \mathrm{O}_{4}$ nanopowders have been synthesised using an LJS method. Gas sensors have been developed from these materials and the morphology, phase composition, optical and magnetic properties of the materials has been evaluated. This is, to the best of our knowledge, the first time that an LJS method has been used to synthesise and compare the gas sensing properties of NiO nanoparticle materials - with a range of particle sizes, shapes and surface areas - to those of $\mathrm{NiFe}_{2} \mathrm{O}_{4}$ nanoparticles. In addition to this, the performance of the LJS Ni-based nanoparticles has been compared to that of a $\mathrm{NiO}$ gas sensor fabricated using a commercially-sourced $\mathrm{NiO}$ powder. This particular sensing array has been tested in the presence of trace gas concentrations of nitrogen dioxide, ethanol, carbon monoxide, acetone and toluene and the optimal operating temperature of these sensor systems has been explored and reported.

\section{Materials and methods}

\subsection{Materials synthesis}

Nanoparticles were produced by M. Ja. Gen's modified levitation-jet method $[31,33]$. In this technique, a metal nickel droplet is suspended inside an appropriate quartz tube and heated up to melting and vaporisation onset by an electromagnetic field $(0.44 \mathrm{MHz})$, generated by a counter-current inductor and supplied from an industrial HF generator. The levitated droplet was blown down by an adjustable stream of $\mathrm{He} / \mathrm{Ar}$ - the main inert gas. Nanoparticle formation occurs at normal gas pressure. As an evaporated material used a wire of pure metal nickel $(0.2 \mathrm{~mm}$ in diameter 99.9 at.\% pure) which, by means of the appropriate feeding device, continuously feeds the liquid droplet with a given constant rate. The vapour condensation rate is made equal to the rate of consumption of the metal wire, which can easily be regulated by varying the rotation speed of the feeding device rollers through a stepped motor. In order to synthesise the $\mathrm{Ni} / \mathrm{NiO}$ nanoparticles, the necessary amount of gaseous oxygen/air was introduced into the main gas stream (in the combined mode $[31,34]$ ). In regards to the synthesis of nickel ferrite, the second Fe wire $(0.3 \mathrm{~mm}$ in diameter, 99.9 at.\% pure) simultaneously supplied the levitated droplet. As-prepared particles were collected on a cloth filter and hereinafter removed into a particle container.

\subsection{Materials characterisation}

The crystal structure and phase compositions of the nanoparticles were determined by X-ray diffraction using a DRON-3M diffractometer
( $\mathrm{Cu} \mathrm{K}_{\alpha}$ or Fe $\mathrm{K}_{\alpha}$ radiation). The XRD phase analysis was performed by the Crystallographica Search-Match (v.3.1.0.2) and PowderCell for Windows (ver. 2.4) programs using a Powder Diffraction File (PCPDFWIN ver. 2.02) database. Powder morphology was examined by transmission electron microscopy (TEM) using JEM-1200EX II (JEOL) operated at an accelerating voltage of $120 \mathrm{kV}$. Electron micrographs were analysed using AxioVision ver. 4.82 image processing program (Carl Zeiss) to determine the average particle size. The specific surface area of the loose nanoparticles was explored using a 4-point method that measures the physical adsorption of nitrogen onto the materials. BET analysis together with a SORBI-M META device was employed to do this.

The UV-vis spectra of the nanoparticles (NPs) were recorded on a Lambda 950 (Perkin Elmer) using an integrated sphere detector. Raman spectra were recorded at room temperature using an InVia Raman Renishaw and confocal microscope Leica DMLM apparatus with an aircooled, charge-coupled device and coupled with He- Cd and Ar lasers emitting at $325 \mathrm{~nm}$ and $514 \mathrm{~nm}$, respectively.

XPS spectra were collected using a Thermo Scientific X-ray Photoelectron Spectrometer. It utilises a monochromated $\mathrm{Al} \mathrm{K \alpha}$ $(1486.6 \mathrm{eV})$ source running at the power of $72 \mathrm{~W}$ with a pass energy of $50 \mathrm{eV}$, which was used for high resolution region scans, and $200 \mathrm{eV}$, which was used for survey scans. Finally, for the charge corrections a 1point scale with the $\mathrm{C} 1 \mathrm{~s}$ peak shifted to $285.0 \mathrm{eV}$ was used. The magnetic properties of the NPs were measured by means of a Quantum Design VSM/SQUID magnetometer, which was calibrated using a $\mathrm{Dy}_{2} \mathrm{O}_{3}$ standard with a relative accuracy of $1 \times 10^{-6} \mathrm{emu}$, at room temperature. During the experiments, the magnetic field was ramped from zero to $70 \mathrm{kOe}$ at $300 \mathrm{~K}$. The sample mass (a few $\mathrm{mg}$ ) was determined with a relative accuracy of $\pm 2 \times 10^{-4} \mathrm{mg}$.

\subsection{MOS sensor fabrication}

The as-prepared nanoparticles were mixed into an ink using a previously reported method [35]. In essence, this process involves mixing the powder under consideration - either the commercial powder (BDH Laboratory supplies, UK) or the fabricated ones - with an organic vehicle, namely, ESL400. The inks were screen printed directly onto gold inter-digitated electrodes on $3 \times 3 \mathrm{~mm}$ alumina chips. They were then treated in a furnace at $600{ }^{\circ} \mathrm{C}$ for one hour to burn the organic phase of the ink off, and ensure adherence of the powders to the sensor substrates [36-38]. Following heat treatment, $50 \mu \mathrm{m}$ platinum wire was spot-welded onto the gold contacts on the fired sensor chips and, in turn, spot-welded on stainless steel pins in moulded polyphenylene sulphide housings that enabled the sensor's suspension in the centre of the housing (Fig. 1). Gas sensing experiments were performed in an inhouse gas-sensing rig [36] designed to maintain up to twelve sensors at a constant operating temperature, which may be modified in the range of $300{ }^{\circ} \mathrm{C}$ to $500{ }^{\circ} \mathrm{C}$, using a heater driver circuit, which is connected to each of the sensors' heater track. The sensors were exposed to a range of BOC gases (ethanol, nitrogen dioxide, acetone, carbon monoxide and toluene) at environmentally-relevant trace gas concentrations [3]. The gas concentrations investigated here are significant in air-quality and environmental monitoring and also in medical and security fields. For the purposes of this paper, sensors were named N1-N6 and specific details of the sensors can be found in Table 1.

\section{Results \& discussion}

\subsection{Powder X-ray Diffraction (PXRD)}

XRD patterns in Fig. 2A show the reflections of pure rhombohedral NiO (JCPDS card No. 44-1159) with lattice parameters: $\mathrm{a}=2.955 \AA$ and $\mathrm{c}=7.228 \AA$. The XRD patterns of samples N2-N5 (see Table 1 for details on the nomenclature and relevant parameters of each sample) have also been included in the figure. For sample N1, cubic Ni 


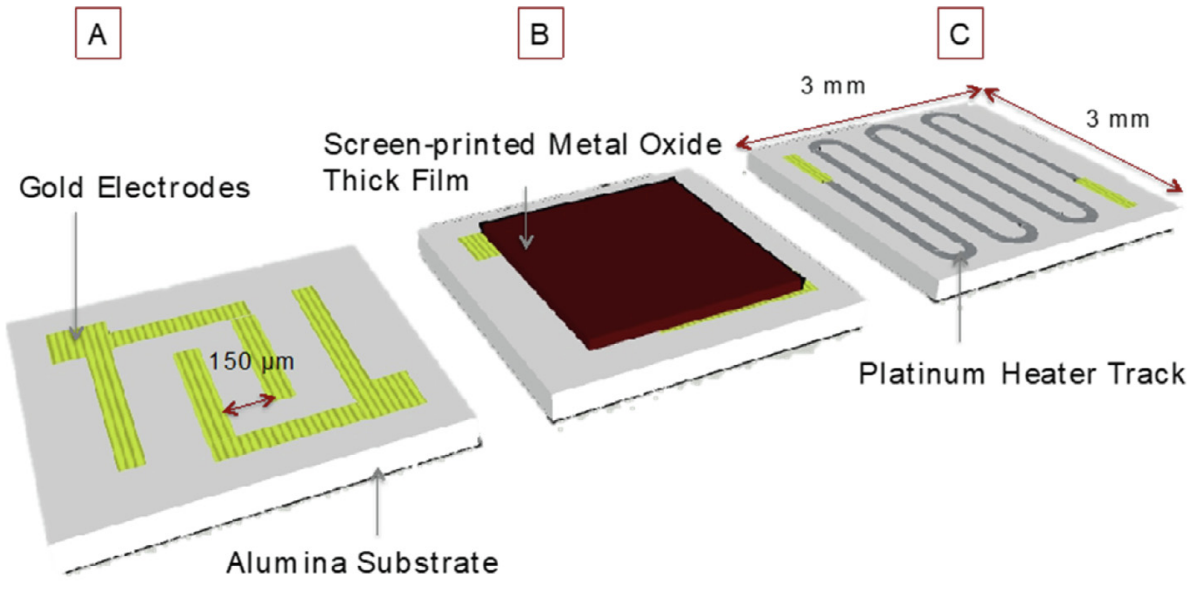

D

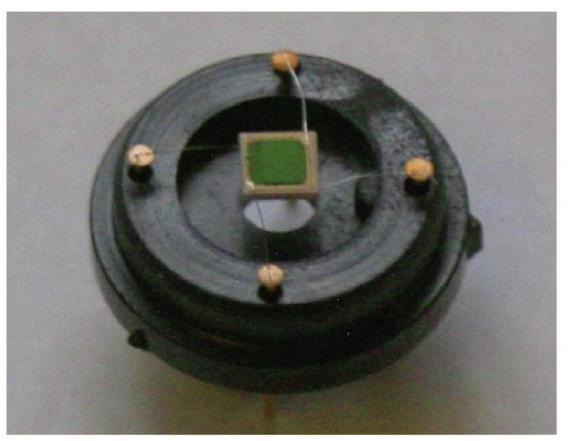

Fig. 1. Sensor substrate schematic showing (A) obverse of sensor with interdigitated gold electrodes (B) alumina substrate with printed metal oxide semiconductor thick film and (C) reverse of sensor showing platinum heater track. Each substrate measures $3 \mathrm{~mm} \times 3 \mathrm{~mm}$. Figure drawn using Google SketchUp 2014 [37]. Construction of a gas sensor device (D). The gas sensitive material is printed on top of gold electrodes on an alumina chip. The reverse side has a platinum heater track on it. The gold electrodes and platinum heater track are attached to the plastic sensor housing by micro-welding $50 \mu \mathrm{m}$ platinum wire between the housing posts and the alumina chip. The complete device will also have a cover which is ommited here for clarity. reflections (JCPDS card No. 04-0850) with $\mathrm{a}=3.524 \AA$ were also identified as the main phase. No other phases or impurities were detected with XRD. Fig. 2B displays the X-ray powder diffraction pattern of the N6 (JCPDS card No. 44-1485) nickel ferrite sample, showing a single phase cubic spinel structure, with lattice parameter $\mathrm{a}=8.339 \AA$. These lattice parameters were identical to those reported in the literature, within experimental error [39].

\subsection{Transmission Electron Microscopy (TEM)}

Transmission electron microscope imaging of the Ni-based nanoparticles (Fig. 3) indicated a cubic morphology with average particle sizes that were less than $100 \mathrm{~nm}$ in all the $\mathrm{Ni} / \mathrm{NiO}$ samples. An exception was observed in the commercially-based N5 material which, in turn, appeared more oval in shape and interconnected and had a particle size that was $>100 \mathrm{~nm}$. The $\mathrm{NiFe}_{2} \mathrm{O}_{4}$ sample (Fig. 3F, sample N6), displayed a significantly different morphology. Its particle shape was predominantly hexagonal. The surface area of the materials - found using BET analysis - proved to be comparable to the mean particle size calculations carried out using relevant micrographic analysis.

\subsection{Raman spectroscopy}

Raman spectroscopy is very sensitive to the microstructure of nanocrystalline materials. It has also been used here to clarify the structure of the Ni-based nanoparticles. The Raman spectrum of pure NiO carried out at room temperature consists of several bands: five vibrational bands of one phonon (1P) TO (at $400-440 \mathrm{~cm}^{-1}$ ) and $\mathrm{LO}$ (at $560 \mathrm{~cm}^{-1}$ ) modes, two-phonon (2P) $2 \mathrm{TO}$ modes (at $740 \mathrm{~cm}^{-1}$ ), $\mathrm{TO}+\mathrm{LO}$ (at $925 \mathrm{~cm}^{-1}$ ) and $2 \mathrm{LO}$ (at $1100 \mathrm{~cm}^{-1}$ ) modes, and twomagnon (2M) bands at $1500 \mathrm{~cm}^{-1}$ [40]. Most of our NiO samples (Fig. 4) show obvious Raman bands located at approximately $380 \mathrm{~cm}^{-1}, 520 \mathrm{~cm}^{-1}, 710 \mathrm{~cm}^{-1}, 880 \mathrm{~cm}^{-1}$ and $1080 \mathrm{~cm}^{-1}$. These Raman shifts are consistent with those of nanosized NiO [41]. The strong band seen at $520 \mathrm{~cm}^{-1}$, belongs to the longitudinal (LO) one phonon (1P) mode and corresponds to the $1080 \mathrm{~cm}^{-1}$, which is due to two phonon (2P) modes of 2LO peak. It was observed that the intensities of two Raman bands increased with increasing nanoparticle size. There was no magnon band in the Raman spectrum, which is normally observed at $1500 \mathrm{~cm}^{-1}$. The absence of a magnon band in the data suggests that a reduction of the spin correlation is the result of a

Table 1

Sample numbers, synthetic conditions and some physico-chemical characteristics of the Ni-based nanoparticles produced by levitation-jet method.

\begin{tabular}{|c|c|c|c|c|c|c|}
\hline Sample ID & Synthesis conditions & $\langle d\rangle(\mathrm{nm})$ & at. $\% \mathrm{NiO}$ & $E_{\mathrm{g}}(\mathrm{eV})$ & $\sigma_{\max }(\mathrm{emu} / \mathrm{g})$ & $\mathrm{S}\left(\mathrm{m}^{2} / \mathrm{g}\right)$ \\
\hline N1 & $\mathrm{He}-500 \mathrm{l} / \mathrm{h}, \mathrm{Ni}-1 \mathrm{~g} / \mathrm{h}$ & 23 & 17 & 2.22 & 42.30 & $29.84 \pm 0.89$ \\
\hline $\mathrm{N} 2$ & $\begin{array}{l}\mathrm{He}-1000 \mathrm{l} / \mathrm{h}, \mathrm{O}_{2}-200 \mathrm{l} / \mathrm{h}, \\
\mathrm{Ni}-1 \mathrm{~g} / \mathrm{h}\end{array}$ & 8 & $\sim 100$ & 2.72 & 0.89 & $103.4 \pm 1.06$ \\
\hline N3 & $\begin{array}{l}\mathrm{He}-1000 \mathrm{l} / \mathrm{h}, \mathrm{O}_{2}-100 \mathrm{l} / \mathrm{h}, \\
\mathrm{Ni}-0.4 \mathrm{~g} / \mathrm{h}\end{array}$ & 7 & $\sim 100$ & 3.28 & 0.998 & $117.2 \pm 1.21$ \\
\hline N4 & Commercial NiO N2 & 230 & $\sim 100$ & 3.18 & 1.81 & $3.77 \pm 0.07$ \\
\hline N5 & $\mathrm{NiO}$ Aldrich 06-67 & 40 & $\sim 100$ & 1.50 & 1.12 & $23.55 \pm 1.69$ \\
\hline N6 & $\begin{array}{l}\mathrm{He}-500 \mathrm{l} / \mathrm{h}, \text { air }-91 / \mathrm{h} \\
\mathrm{Ni}-2 \mathrm{~g} / \mathrm{h}, \mathrm{Fe}-3.5 \mathrm{~g} / \mathrm{h}\end{array}$ & 31 & 0 & - & 69.0 & $36.27 \pm 3.73$ \\
\hline
\end{tabular}



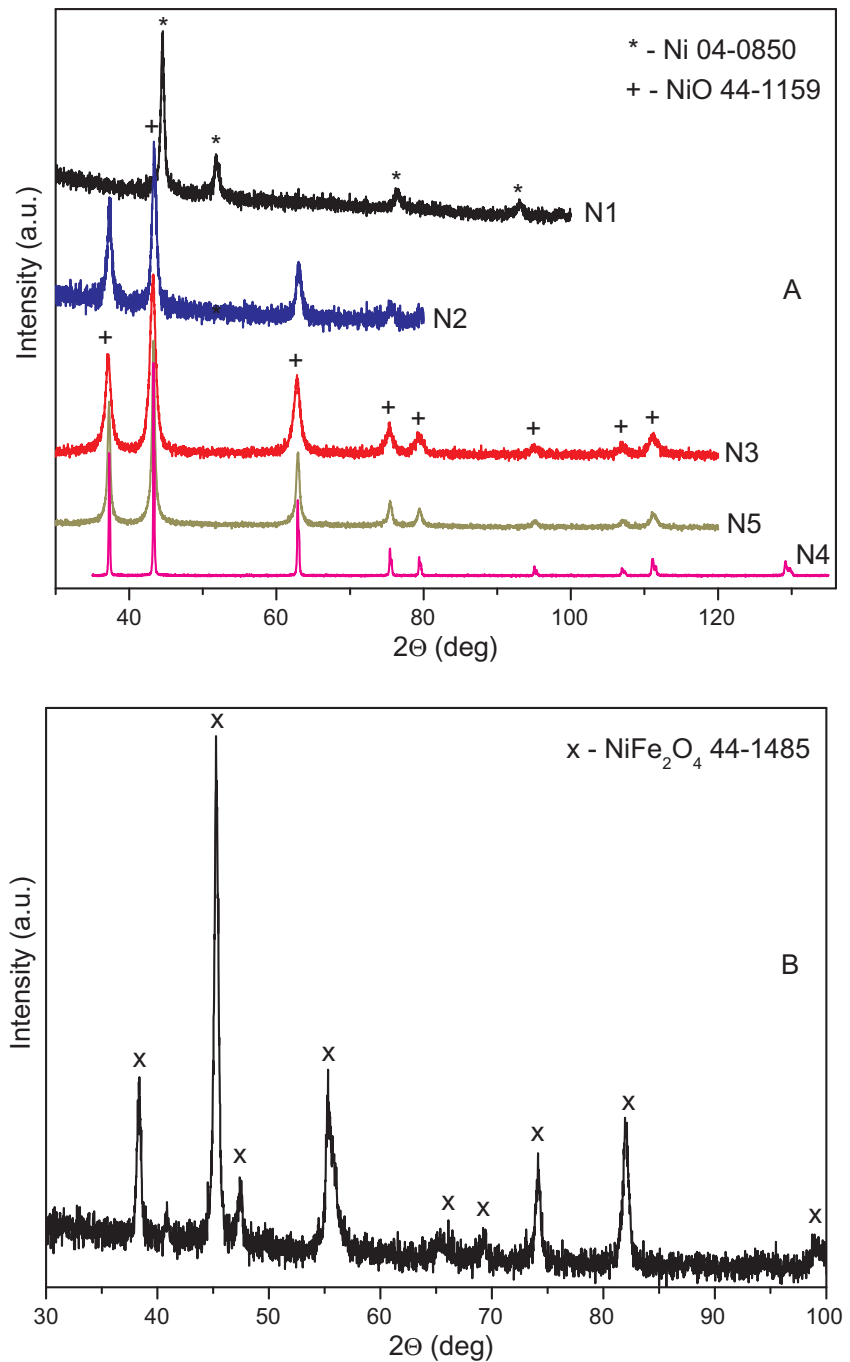

Fig. 2. (A) X-ray diffraction patterns of Ni-based nanoparticles and (B) of the $\mathrm{NiFe}_{2} \mathrm{O}_{4}$ (N6) sample. The sample nomenclature corresponds to that presented in Table 1.

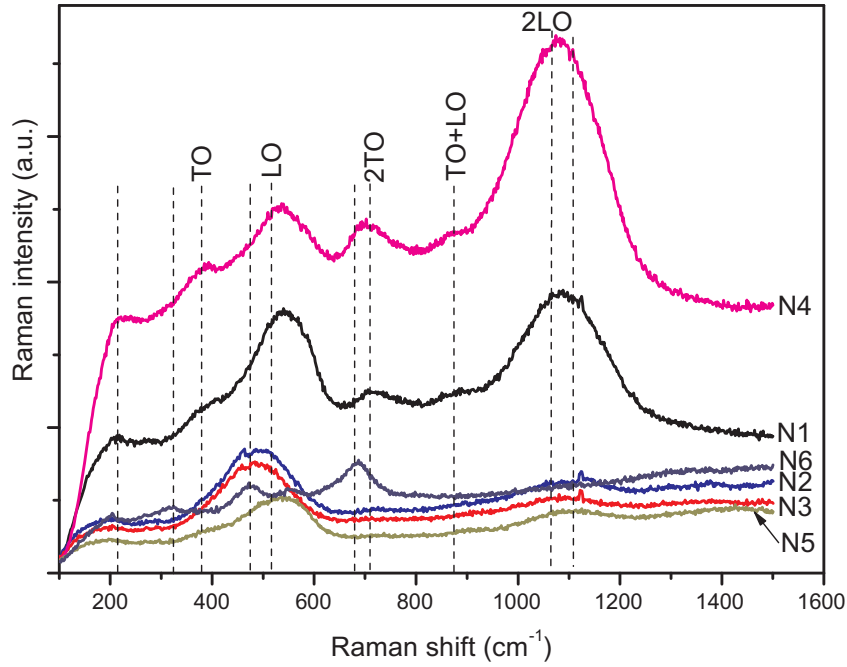

Fig. 4. Raman spectra of the Ni-based nanoparticles. The curve numbers correspond to the sample IDs presented in Table 1.

phase transition from antiferromagnetic to paramagnetic, when the particle size is reduced to the nano level [42]. From this, it can be concluded that a reduction in nanoparticle sizes of $\mathrm{NiO}$ samples leads to a transformation into a paramagnetic phase.

\subsection{UV-vis spectroscopy}

UV-vis diffuse reflectance spectra are presented in Fig. 5A for some of the samples investigated in this study. At long wavelengths, the long tail of the reflectance is attributed to the scattered radiation of nickel oxide clusters of nanoparticles. All the spectra were analysed using the Kubelka-Munk function $F(R)$ [43], which is related to the diffuse reflectance as follows:

$\mathrm{F}=(1-\mathrm{R})^{2} / 2 \mathrm{R}$

Here, $\mathrm{R}$ is the absolute reflectance and $\mathrm{F}$ is an equivalent to the absorption coefficient. A better approach is to determine the indirect band gap, $\mathrm{E}_{\mathrm{g}}$, of the nanoparticles, which was estimated by plotting (FE) ${ }^{0.5}$ as a function of photon energy E (Fig. 5B) - according to [44]. The linear

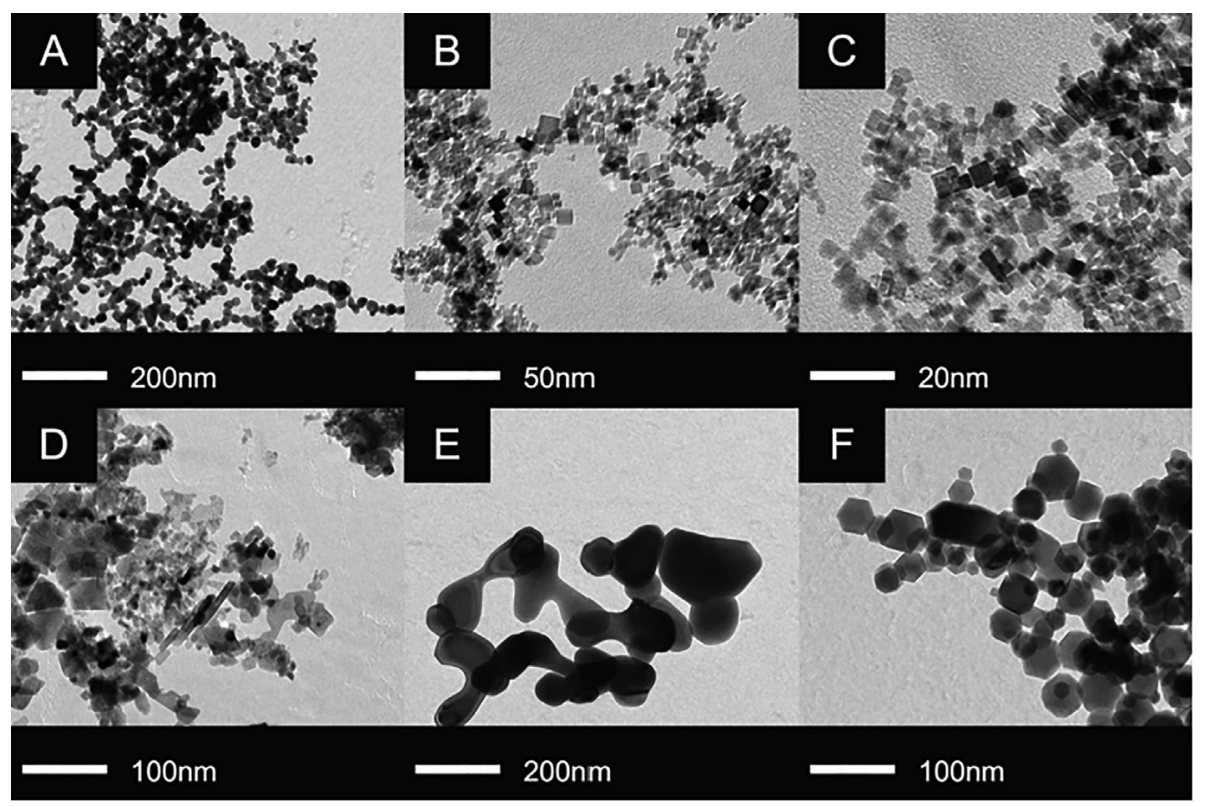

Fig. 3. TEM images of Ni-based nanoparticles A) N1 B) N2 C) N3 D) N4 E) N5 F) N6 (all the sample numbers are detailed in Table 1). 

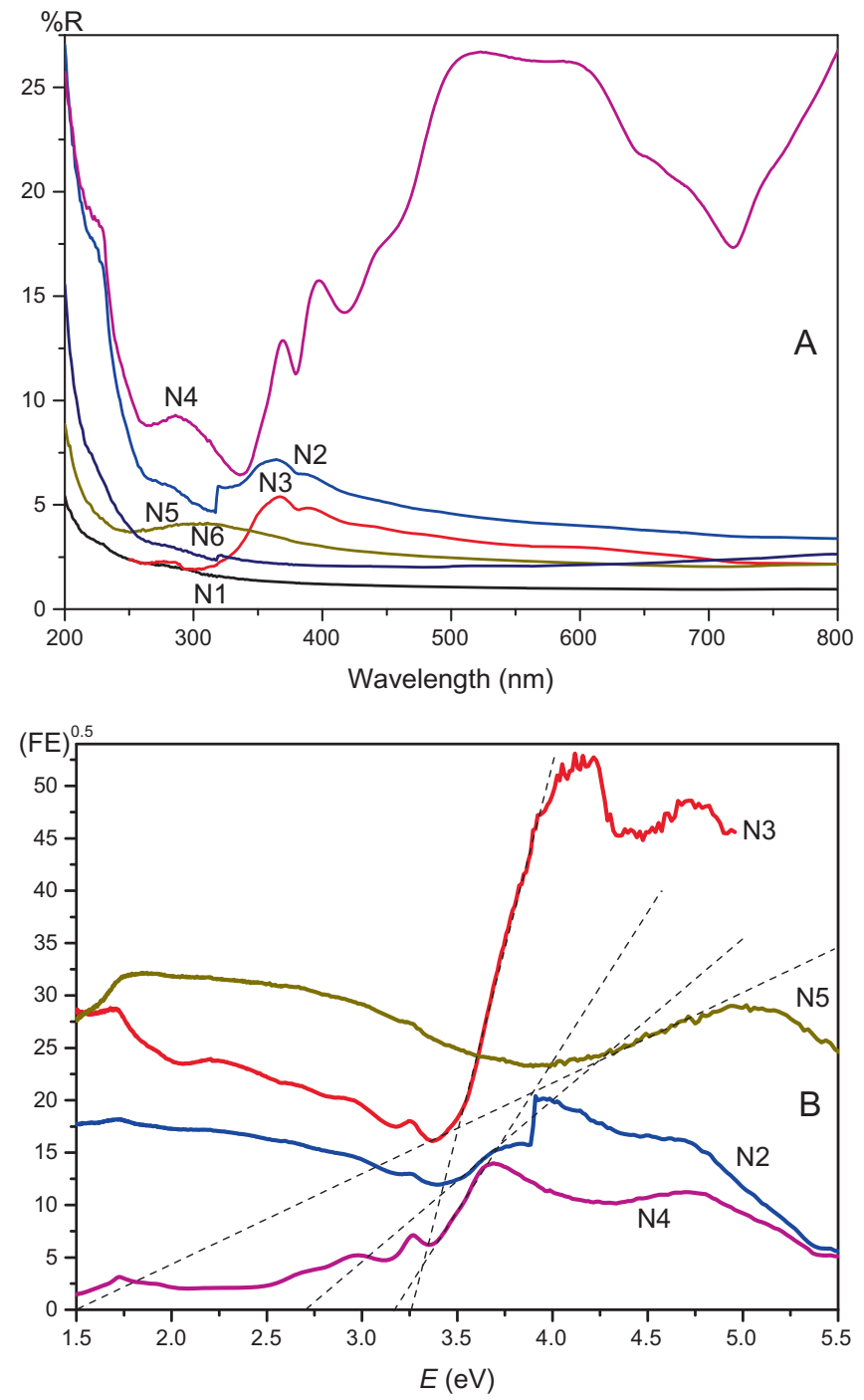

Fig. 5. (A) UV-vis diffuse reflectance spectra and (B) band gap of the Ni-based nanoparticles plotted using the Kubelka-Munk function. Sample nomenclature corresponds to that presented in Table 1.

portion of the curves was extrapolated to zero in order to determine the band gap value [45]. Analysis of Fig. 5B revealed that, for the largesized nanoparticles, large variations in reflectance with wavelength were observed, when compared to the small-sized nanoparticles. No linear relation with the Tauc plot for (FE) ${ }^{2}$ [46] was found, suggesting that Ni-based oxide nanoparticles are semiconducting, with indirect transition to the band gap energy, which is in stark contrast with previously reported data [47].

\subsection{XPS spectroscopy}

The surface composition and chemical states of the materials were determined by means of XPS spectroscopy, according to the characteristic binding energies of the different elements on the materials' surfaces. The varied physical properties of Ni-based nanoparticles are due to the dominant contributions from its defect structure; particularly, the cation $\left(\mathrm{Ni}^{2+}\right)$ and anion $\left(\mathrm{O}^{2-}\right)$ vacancies, which are the major source of defects in $\mathrm{NiO}$ [48]. The presence of each $\mathrm{Ni}^{2+}$ vacancies in the lattice leads to the transformation of two adjacent $\mathrm{Ni}^{2+}$ ions into $\mathrm{Ni}^{3+}$ ions to acquire charge neutrality, thereby inducing a lattice distortion. Each $\mathrm{Ni}^{2+}$ vacancy along with two $\mathrm{Ni}^{3+}$ ions in opposite nearest neighbour positions constitute a bound quadrupole. If a $2 p$
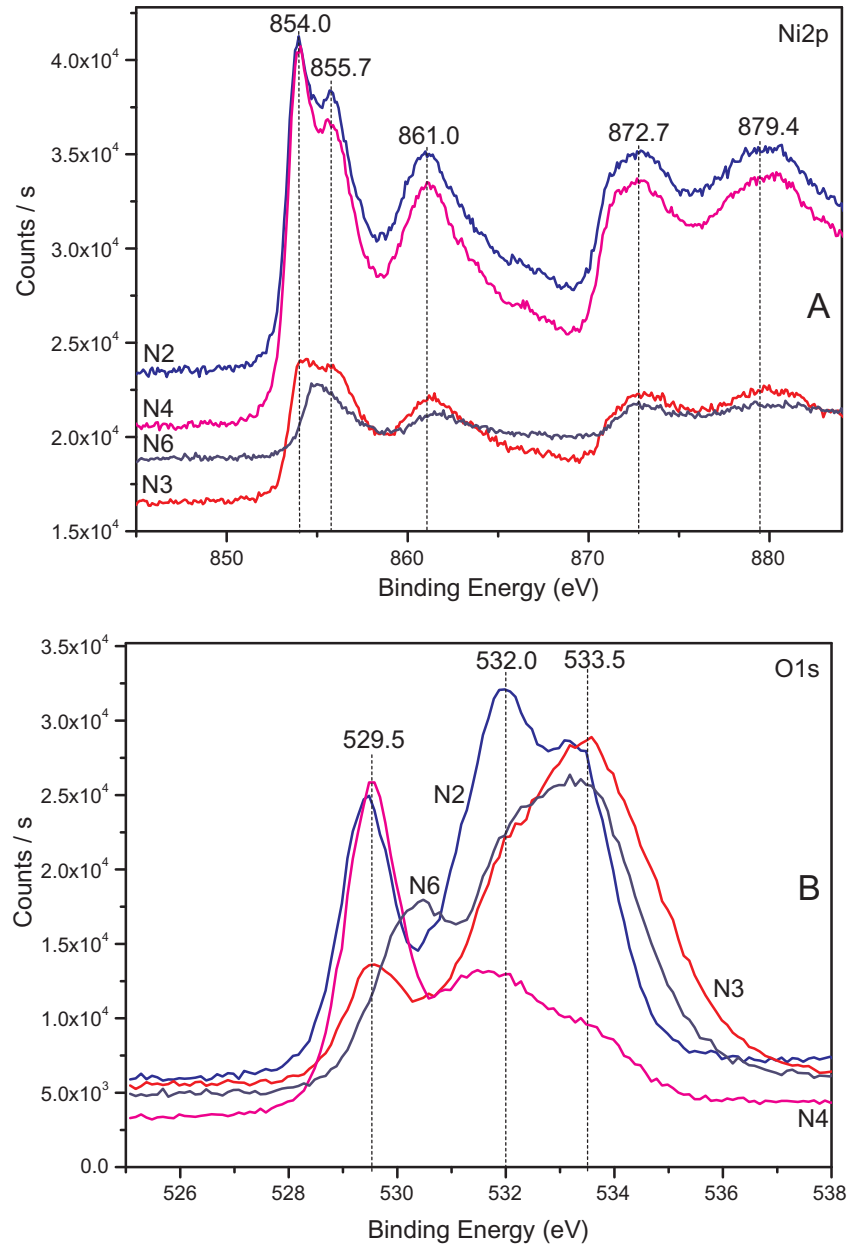

Fig. 6. (A) X-ray photoelectron spectra of Ni 2p and (B) O 1s spectra and of the Ni-based nanoparticles. Sample nomenclature corresponds to the sample IDs presented in Table 1.

electron from the nearby $\mathrm{O}_{2}{ }^{-}$ion is transferred to a $\mathrm{Ni}^{3+}$ ion of the quadrupole, then a hole will be induced in the $2 \mathrm{p}$ band of $\mathrm{O}^{2-}$ [49]. The presence of $\mathrm{Ni}^{3+}$ ions in the samples was established by XPS measurements, the results of which are shown in Fig. 6A and 6B. The two sharp peaks at $854.0 \mathrm{eV}$ and $872.7 \mathrm{eV}$ in the $\mathrm{Ni} 2 \mathrm{p}$ spectrum correspond to $\mathrm{Ni} 2 \mathrm{p}_{3 / 2}$ and $\mathrm{Ni} 2 \mathrm{p}_{1 / 2}$ (Fig. $6 \mathrm{~A}$ ).

Satellite peaks at $879.4 \mathrm{eV}$ and $861.0 \mathrm{eV}$ are present as a result of the shake-up processes [50]. In regards to the O 1s spectra of the N2 (Fig. 6B) sample, the peaks that appear at about $529.5 \mathrm{eV}$ and $532.0 \mathrm{eV}$ correspond to the $\mathrm{O}^{2-}$ ions bonded to $\mathrm{Ni}^{2+}$ and $\mathrm{Ni}^{3+}$, respectively. For the N3 sample, corresponding peaks were obtained at $529.7 \mathrm{eV}$ and $533.5 \mathrm{eV}$. After comparison of the peak intensities of the two samples, it was clear that the presence of $\mathrm{Ni}^{3+}$ in the last sample had diminished considerably [48]. Hence, it may be concluded that the presence of uncompensated $\mathrm{Ni}^{2+}$ vacancies are less and, as such, the concentration of $\mathrm{O}^{2-}$ vacancies is comparatively more abundant in the last sample and in the ferrite material as well (sample N6). Another plausible interpretation for the peak observed near $856 \mathrm{eV}$ can be found in [51]. This spectrum cannot be satisfactorily fitted with the unaltered $\mathrm{Ni}^{2+}$ multiplets (as it was the case for sample N6) or with the FWHM variation alone. A satisfactory fit can only be achieved by allowing variation in the $\mathrm{BE}$ positions of the multiplet contributions to the main peak.

There is also a broad peak associated with other intrinsic losses at a higher binding energy than that of the main peak multiplets. In all of the above-mentioned cases, this contribution is necessary in order to model the valley between the main peak and the satellite structures and 

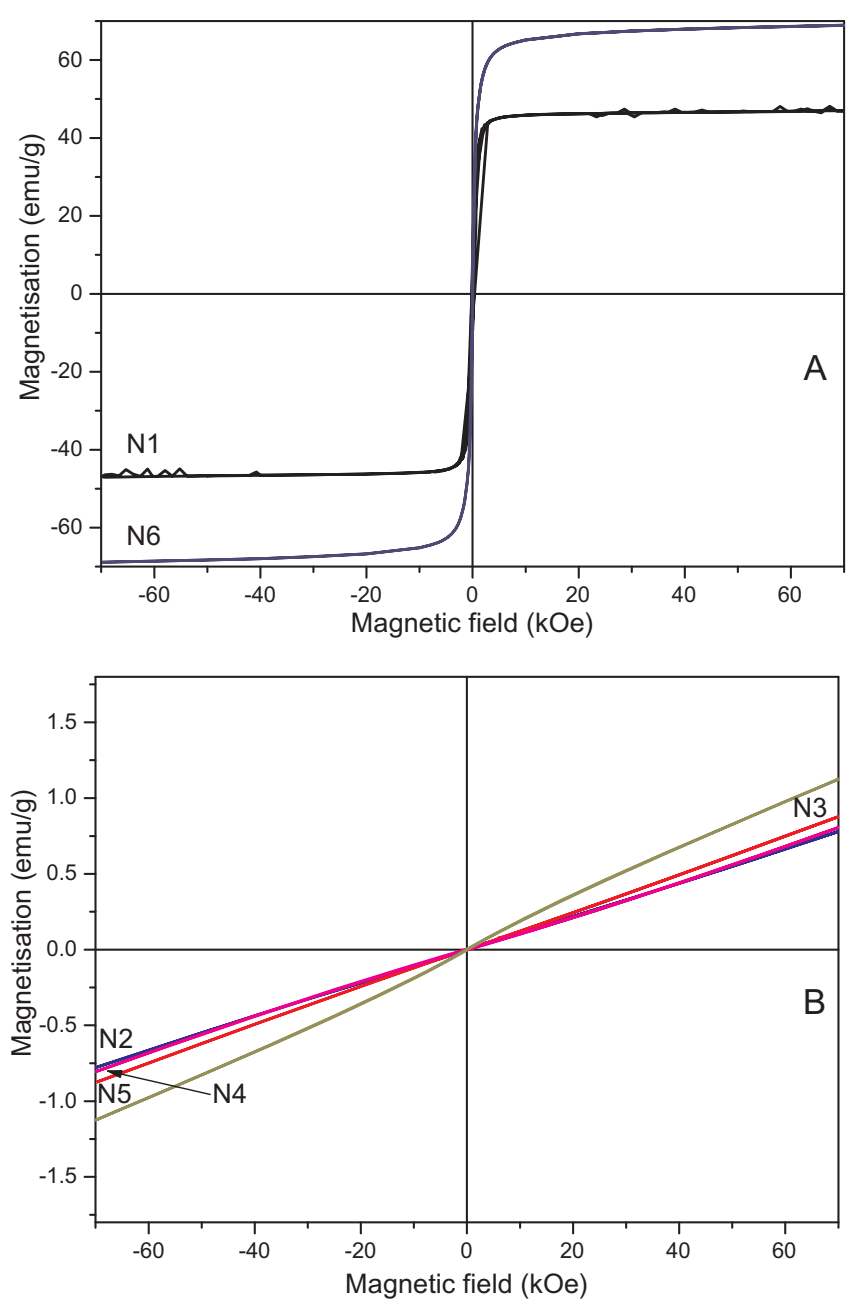

Fig. 7. (A) Hysteresis loops of the Ni-based nanoparticles with sample ID N1 and N6 and (B) hysteresis loops of the Ni-based nanoparticles with sample IDs N2-N5. Sample nomenclature corresponds to the samples IDs listed in Table 1.

is consistent with the inter-band losses [51]. In the Fe 2p spectra (sample N6), the peak shape was very broad, which may indicate several Fe-containing species e.g. $\mathrm{Fe}-\mathrm{OH}$. Fitting suggests that the chemical state of the iron was largely $\mathrm{Fe}^{3+}$. However, the presence of some $\mathrm{Fe}^{0 .} \mathrm{Fe}^{2+}$ cannot be ruled out.

\subsection{Magnetic measurements}

In the field of magnetic gas sensing, it has been demonstrated that spintronics will allow to overcome the limitations of the present conductometric nanostructured devices, such as the high working temperatures [52]. This condition, for instance, might undermine safety during hydrogen leak detection. The reaction process has to be reversible, therefore, the ferromagnet must be protected to preserve its magnetic properties [53]. Matatagui et al. has been proposed an innovative gas sensor constitutes by $\mathrm{CuFe}_{2} \mathrm{O}_{4}$ ferromagnetic nanoparticles [54]. To study magnetic properties of ferromagnetic and antiferromagnetic materials as gas sensing parameters [55] we measured magnetic hysteresis loops at room temperature for the samples prepared under non-oxidising conditions and ferrite (N1, N6), as well as those prepared under oxidising conditions (N2-N5) are shown in Fig. 7.

Magnetic characterisation revealed that samples N1, N6 showed ferromagnetic-like hysteresis loops (Fig. 7A). Saturation magnetisation values at $300 \mathrm{~K}$ increased with the $\mathrm{Ni}$ content in sample N1, approaching that of bulk $\mathrm{Ni}$ at $300 \mathrm{~K}(55 \mathrm{emu} / \mathrm{g})$. In Fig. 7B, a set of hysteresis loops of selected samples, previously listed in Table 1 , is plotted. All loops showed almost superparamagnetic behaviour with very little hysteresis and with coercivity lower than 100 Oe. Specific magnetisation $\sigma_{\mathrm{r}}$ showed a nearly linear dependence at high fields and reached maximum values under $1 \mathrm{emu} / \mathrm{g}$ at $70 \mathrm{kOe}$ [56].

\section{Gas-sensing}

The gas-sensing properties of $\mathrm{NiO}$ nanoparticles and of $\mathrm{NiFe}_{2} \mathrm{O}_{4}$ fabricated with an LJS method were investigated in this study. These were, in turn, compared to the sensing properties of a NiO sensor that was fabricated using a commercial powder. Bearing in mind that MOSbased sensors often see a so-called 'sensitivity maximum' when they are exposed to a test gas and heated to temperatures that typically fall in the range of $200-500{ }^{\circ} \mathrm{C}$, [57] it was key to understand how the newlyfabricated sensors behaved under different experimental conditions and how these might improve or worsen the sensitivity and/or selectivity of the devices towards test gases.

Although the explications behind the resistance change that occurs in a MOS sensor when it is exposed to a gas are still a subject of debate, it is generally accepted that resistance changes occur either due to (1) space charge layer effects and surface potential variations - brought about by ionosorbed gaseous species, or (2) as a result of changes in the oxygen stoichiometry of the sensing material being used [58-61]. It is typical to observe n-type semiconductor materials responding with a decrease in sensor resistance when presented with an inflammable or reducing gas and, conversely, to respond by increasing in resistance when presented with an oxidising gas [6]. P-type semiconductor materials will display opposing behaviours. That is, when supplied with an inflammable gas they will increase in resistance and, in the presence of an oxidising gas, they will decrease in resistance. The literature sometimes reports variations of this expected behaviour [60-63].

$\mathrm{NiO}$ is a p-type semiconductor material and its suitability as a gas sensor has already been established in the literature. The sensing properties of $\mathrm{NiFe}_{2} \mathrm{O}_{4}$ have also been reported in other studies. It is commonly a p-type semiconductor, its behaviour stemming from the hole $\left(\mathrm{h}^{+}\right)$hopping between $\mathrm{Ni}^{2+}$ and $\mathrm{Ni}^{3+}$ in octahedral sites, as follows [64]:

$\mathrm{Ni}^{2+}+\mathrm{h}^{+\circ} \leftrightarrow \mathrm{Ni}^{3+}$

It must be noted that the $\mathrm{Ni}^{3+}$ in $\mathrm{NiFe}_{2} \mathrm{O}_{4}$ comes from cation vacancies. These form because of nickel's draw to excess oxygen during synthesis [64]. In order to keep the electrical charge of the lattice neutral, $\mathrm{Ni}^{2+}$ then oxidises to $\mathrm{Ni}^{3+}$ [64]. There are certain configurations that might be beneficial for the purposes of gas sensing. In essence, when the $\mathrm{NiFe}_{2} \mathrm{O}_{4}$ contains a lower concentration of $\mathrm{Ni}^{3+}$, in relation to that of $\mathrm{Ni}^{2+}$, a higher concentration of oxygen species may chemisorb on the sensor surface - believed to lead to enhanced sensor responses towards test gases.

\subsection{Sensor exposure to ethanol}

The sensors were most responsive to ethanol gas at $300^{\circ} \mathrm{C}$. This can be observed in Fig. 8, where the sensor responses to $100 \mathrm{ppm}$ of the gas have been illustrated at various temperatures. Fig. 9 shows the sensor responses and peak shape patterns attained when exposing the sensors to different concentrations of ethanol at $300{ }^{\circ} \mathrm{C}$. In the latter figure, it can be seen that the nickel ferrite sensor was consistently the most responsive one to ethanol and it displayed flat peak shape characteristics that are commonly sought in practical settings. More specifically, the sensor saturated and reached steady state, particularly when exposed to $50 \mathrm{ppm}, 80 \mathrm{ppm}$ and $100 \mathrm{ppm}$ of the gas. As expected, at lower operating temperatures the sensors' response times were longer and ranged between 99 and $299 \mathrm{~s}$, which could be undesirable in practical applications. These results are in line with what other studies investigating NiO-based nanoparticles have reported [65]. With lower ethanol concentrations, the sensors took even longer times to respond. 


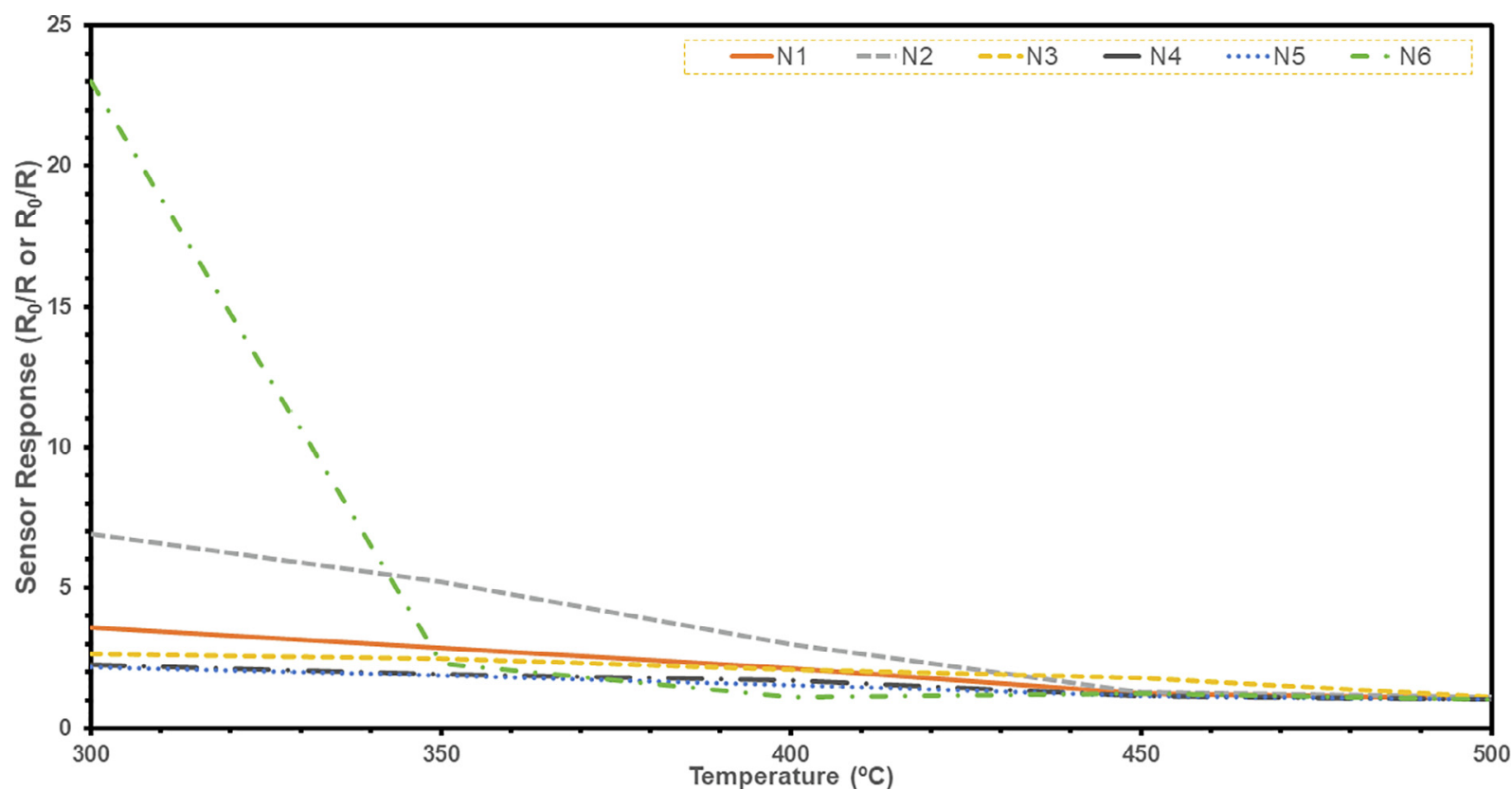

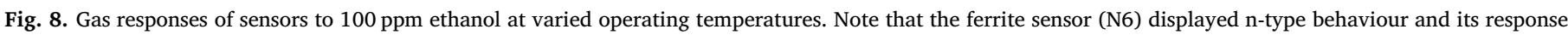
was therefore calculated as $R_{0} / R$.

In regards to the recovery times of the sensors, most failed to fully recover in the allocated recovery time. Nevertheless, the nickel ferrite sensor fully recovered in just over a minute. It must be noted that the shark-fin shape that is observed in some sensors is indicative of an unsaturated surface, and suggests that the dynamic range of the sensors is greater than that investigated here.

It is interesting to see that the greater surface area of some sensors, namely $\mathrm{N} 2$ and $\mathrm{N} 3\left(\mathrm{~S}=103 \mathrm{~m}^{2} / \mathrm{g}\right.$ and $\mathrm{S}=117 \mathrm{~m}^{2} / \mathrm{g}$, respectively $)$ did not lead to the expected improvements in sensor response that were observed with sensor N6 (nickel ferrite) which, in turn, had a surface area of $36.2 \mathrm{~m}^{2} / \mathrm{g}$ and larger particle size of $\sim 31 \mathrm{~nm}$, in relation to $8 \mathrm{~nm}$ and $7 \mathrm{~nm}$ of samples N2 and N3, respectively. The N4 (LJS-synthesised) and N5 (commercial NiO powder) sensors responded to ethanol gas comparatively, which could be due to their similar surface area. This was in spite of the larger particle size of the N5 material and their very different particle morphology (Fig. 2D and 2E). It is thought that the enhanced responsiveness to ethanol seen in sensor N2 was because of its higher surface area and higher concentration of surfacereactive sites available for gas interaction. It is thought that a more open and porous sensing material microstructure can result in an amplification in the material's conductivity [7]. It must be noted, however, that despite the similarities in surface area and particle size of sensors $\mathrm{N} 2$ and N3, the responsiveness of the latter to ethanol was more conservative. It is possible that the microstructure of this sensor was affected differently during the sensor's heat treatment process, leading to the observed lower sensor responses. Sensing materials with different particle shapes can provide adsorption sites for gases with different energies [20]. As such, it is interesting to see that sensors N1 and N2,

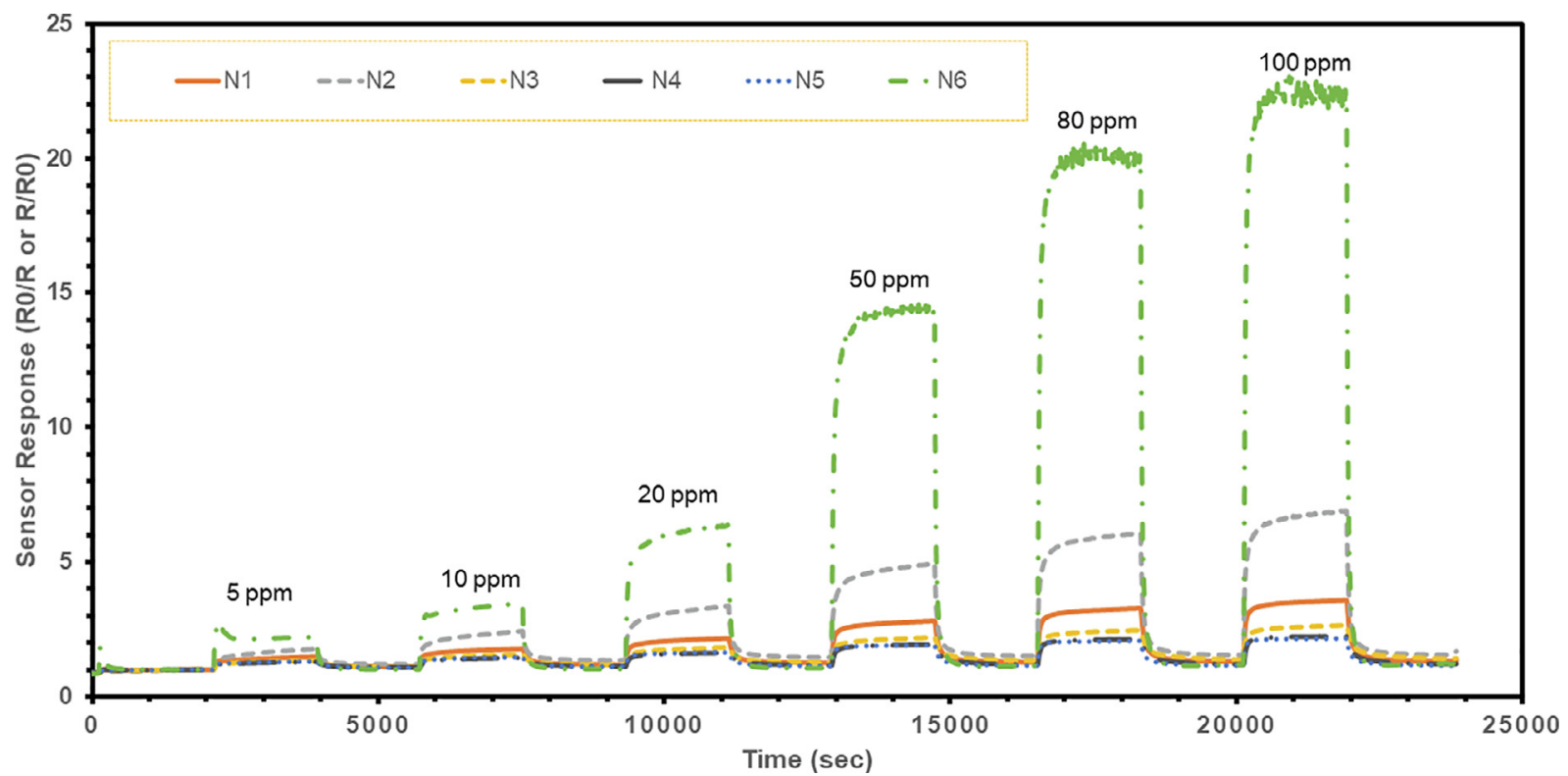

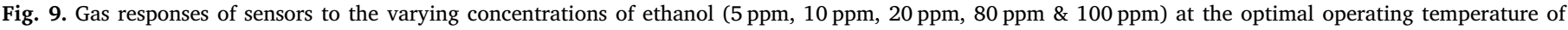
$300^{\circ} \mathrm{C}$. Note that the ferrite sensor (N6) displayed n-type behaviour its response was therefore calculated as $R_{0} / R$. 
for instance, displayed very different particle sizes and shapes, yet they were both responsive to ethanol at $300{ }^{\circ} \mathrm{C}$, rendering them as promising gas sensor candidates, particularly when supplied with ethanol concentrations that were equal to or exceeded $50 \mathrm{ppm}$. As suggested previously, the relatively high sensitivity of the $\mathrm{NiFe}_{2} \mathrm{O}_{4}$ sensor may be due to the number of step and kink sites in the morphology of the sensor. It is possible that this morphology promotes the better adsorption and ionisation of oxygen at the interface of the materials, thus leading to the observed enhanced sensor responses $[66,67]$.

Other studies have also investigated Ni-based materials for ethanol detection. For instance, in [19], $\mathrm{NiO} / \mathrm{NiFe}_{2} \mathrm{O}_{4}$ composites were prepared to determine the sensing performance of the new sensors at room temperature. The sensors showed good sensitivity to gases such as ethanol, acetone, THF and methanol. However, the concentrations tested were well in excess of concentrations sought in environmentalmonitoring practices. In [68], a NiO nanoplate sensor was modified by mixture with a $\mathrm{ZnO}$ material to obtain selectivity towards $500 \mathrm{ppm}$ ethanol gas $\left(R / R_{0}=\sim 35\right.$, in relation to $R / R_{0}<2.5$ that they obtained with sensor exposure to gases such as $\mathrm{CO}, \mathrm{H}_{2}, \mathrm{H}_{2} \mathrm{~S}$ ).

\subsection{Sensor exposure to acetone}

In regards to the sensor responses towards acetone gas (Fig. 10), it can be seen that, in this instance, sensor responsiveness was more prominent at $350^{\circ} \mathrm{C}$, rather than at $300{ }^{\circ} \mathrm{C}$ (see exposure to ethanol gas above). At the latter temperature, the sensors presented characteristics that would be considered unfavourable if used in practical applications, such as long response and recovery times of the sensors.

It can also be observed in Fig. 10 that heating the sensors to $350{ }^{\circ} \mathrm{C}$ directly affected the peak shape of the sensors upon exposure to the acetone, leading to faster response times, as expected. This is because thermal excitation leads to accelerated surface reactions and the penetration depth of the gases into the sesing system becomes limited, as gases are consumed in the outermost layer of the material $[69,70]$. As the operating temperature was incremented to $400{ }^{\circ} \mathrm{C}, 450{ }^{\circ} \mathrm{C}$ and $500{ }^{\circ} \mathrm{C}$, sensor responses diminished in magnitude and sensor $\mathrm{N} 3$, for instance, continuously failed to recover when the supply of gas was switched off.
The nickel ferrite sensor provided the most responsive outputs to acetone across the selection of temperatures investigated. Although the latter provided n-type responses in relation to the p-type responses attained with the remaining sensors, a mere comparison of the response magnitudes of the sensors revealed an 8-fold enhancement of the $\mathrm{NiFe}_{2} \mathrm{O}_{4}$ sensor, in relation to the N5 sample (NiO sensor prepared with a commercial powder). As it occurred with sensor exposure to ethanol gas, the $\mathrm{N} 2$ sensor was more responsive to acetone than the other NiObased (LJS and commercially-based) sensors. At $350{ }^{\circ} \mathrm{C}$, the remaining sensors (N3-N5) responded very similarly to acetone, providing no significant differences in magnitude of response and peak shape patterns (Fig. 10).

The literature reports studies that fabricated $\mathrm{NiO} / \mathrm{ZnO}$ hierarchical nanostructured composites, which displayed great responsiveness to $100 \mathrm{ppm}$ acetone both at $300^{\circ} \mathrm{C}$ and $350^{\circ} \mathrm{C}$, with $\mathrm{R}_{0} / \mathrm{R}>100$ and $\sim 50$, respectively. Other groups that synthesised $\mathrm{NiO} / \mathrm{ZnO}$ hollow spheres attained sensor responses $\mathrm{R}_{0} / \mathrm{R}=5$ towards $100 \mathrm{ppm}$ of acetone at $350{ }^{\circ} \mathrm{C}$. In [71] a Ca-doped $\mathrm{NiFe}_{2} \mathrm{O}_{4}$ sensor displayed selectivity towards acetone. Nevertheless, the concentrations tested were not specified, making it difficult to compare their results to the ones reported here.

\subsection{Sensor exposure to toluene}

Sensors were also exposed to toluene gas, the results of which are presented in Fig. 11. As observed in the figure, the sensors were most responsive to toluene at $350{ }^{\circ} \mathrm{C}$.

With the exception of the N6 (nickel ferrite) sensor, which was the most responsive to the gas, the other LJS-based nanoparticle sensors and the commercially-based $\mathrm{NiO}$ sensor were not particularly sensitive to toluene. It is noteworthy that the N6 sensor was responsive to trace concentrations of toluene i.e. $2.5-50 \mathrm{ppm}$ and, for this reason, lower concentrations would be worth testing in future. The sensor responded linearly when supplied with toluene concentrations ranging between 2.5 and $25 \mathrm{ppm}$. The response vs. concentration curve appeared to saturate when supplied with higher concenrations of toluene, suggesting a limited dynamic range of the sensor towards this gas. At $350{ }^{\circ} \mathrm{C}$, the nickel ferrite sensor provided a $\sim 4.8$ enhancement in sensor response
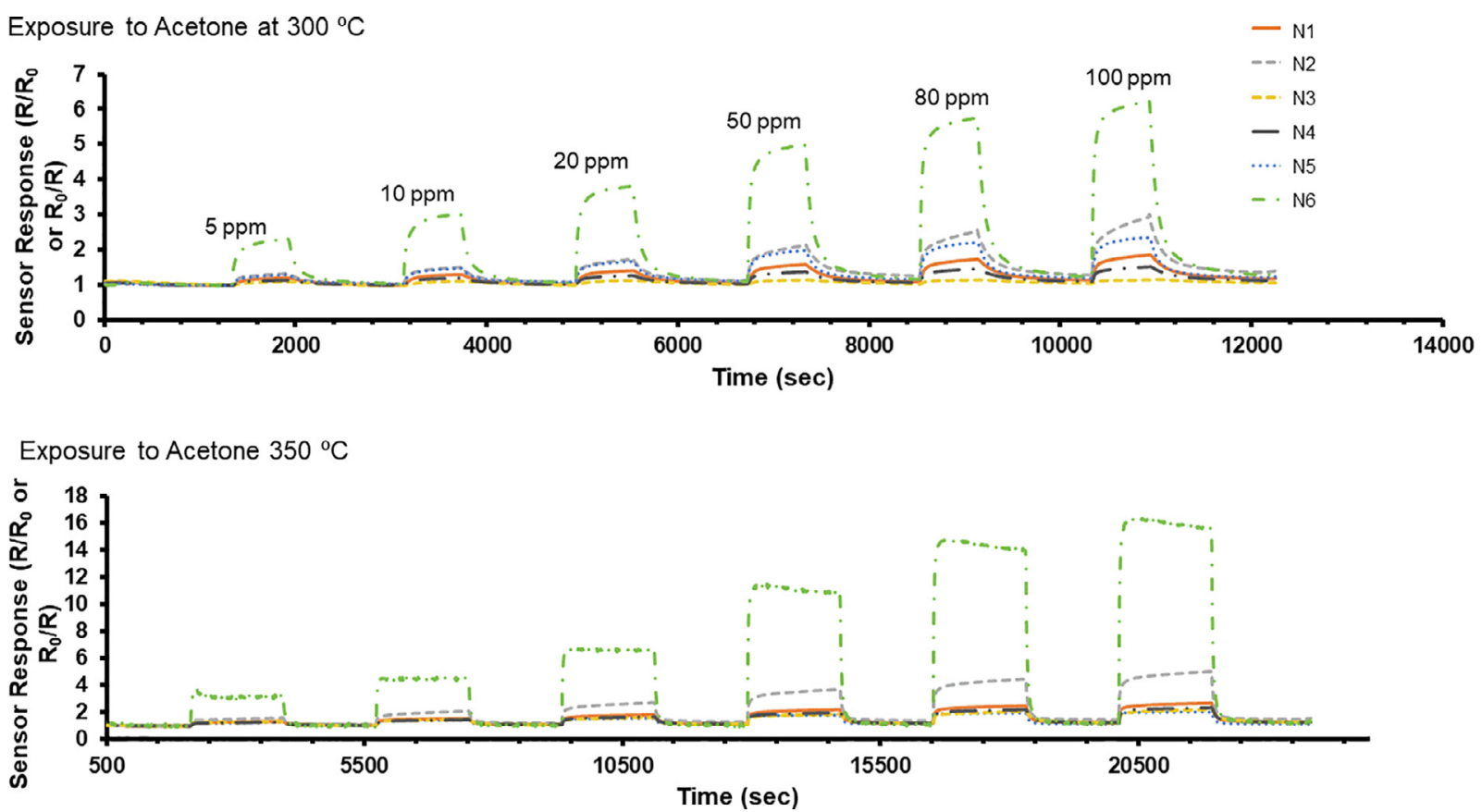

Fig. 10. Gas responses of sensors to the varying concentrations of acetone ( $5 \mathrm{ppm}, 10 \mathrm{ppm}, 20 \mathrm{ppm}, 50 \mathrm{ppm}$ and $100 \mathrm{ppm}$ ) at an operating temperature of $300{ }^{\circ} \mathrm{C}$ (top image) and $350^{\circ} \mathrm{C}$ (bottom image). Note that $\mathrm{N} 6$ behaved as an n-type semiconductor its response was thus calculated as $\mathrm{R}_{0} / \mathrm{R}$. 


\section{Exposure to Toluene $350^{\circ} \mathrm{C}$}
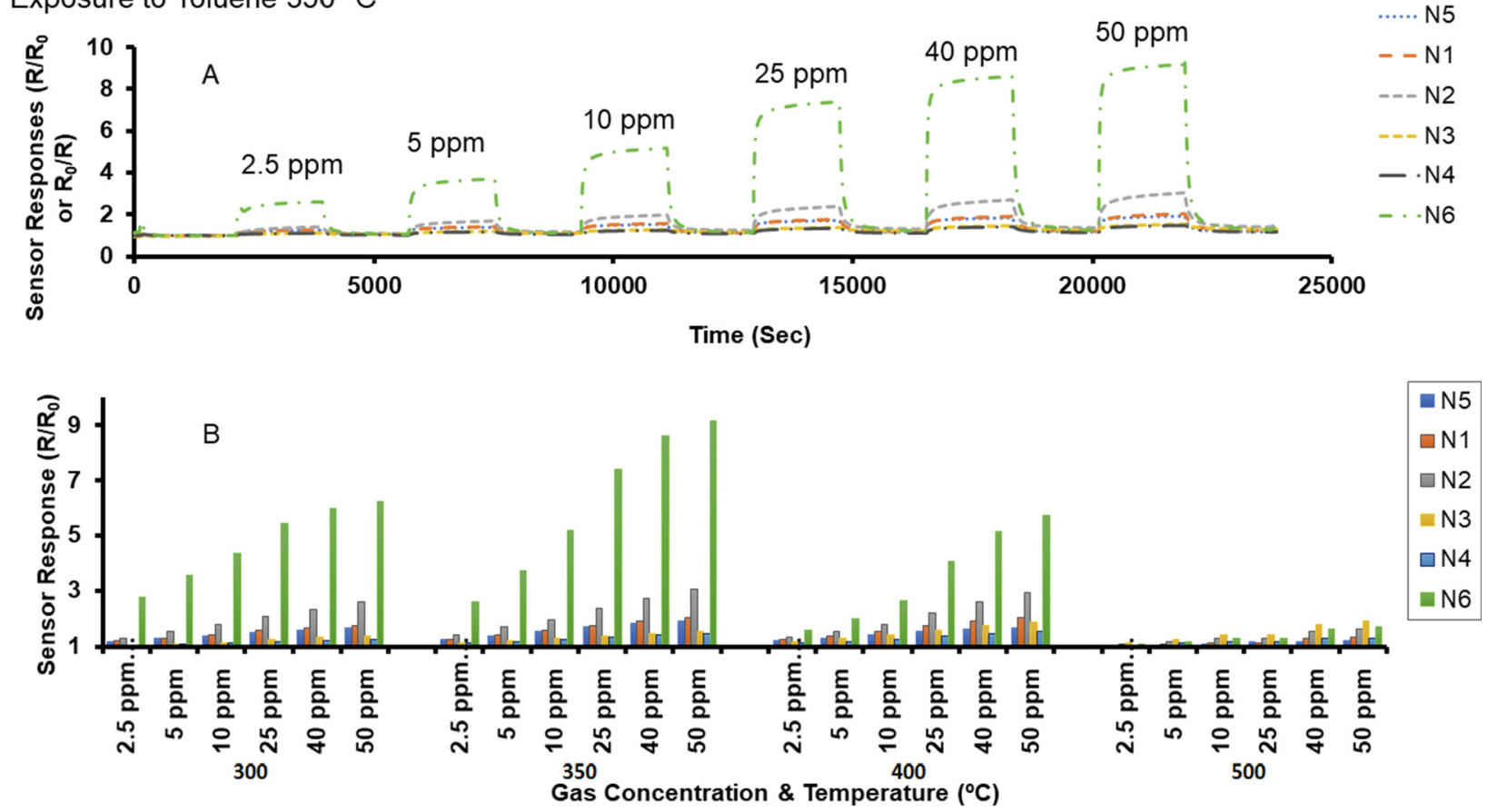

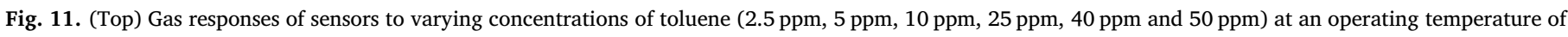

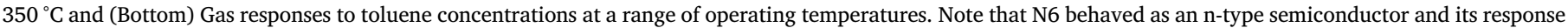
was thus calculated as $R_{0} / R$.

over the commercially-sourced $\mathrm{NiO}$ sensor (N5), when supplied with $50 \mathrm{ppm}$ of gas.

Sensor N2 also provided promising outcomes for toluene detection, albeit the rather conservative response attained, in relation to that of sensor N6. Sensors N1, N3, N4 and N5 responded very similarly to toluene, despite the important differences in surface area, particle size, morphology and synthesis procedure.

$\mathrm{NiO}$ nanostructures have been proposed in the literature as a great material for the detection of toluene, particularly when doped with chromium [72]. The Cr-doped nanostructures were found to be selective towards the gas, in relation to the responses that were attained when exposing the sensor to molecules with similar molecular structures e.g. benzene and xylene. Other studies have utilised $\alpha-\mathrm{Fe}_{2} \mathrm{O}_{3} / \mathrm{NiO}$ composites with a hollow nanostructure for the selective detection of the gas [73]. The response magnitude of the composite sensor they investigated was comparable to that of the $\mathrm{NiFe}_{2} \mathrm{O}_{4}$ sensor presented here when exposed to concentrations of $5 \mathrm{ppm}$ and $10 \mathrm{ppm}$.

Other studies that fabricated $\mathrm{NiFe}_{2} \mathrm{O}_{4}$ using an inverse titrating chemical co-precipitation technique reported lower sensing responses to higher concentrations of toluene than reported here [74]. However, their sensor displayed selectivity towards toluene, in relation to other gases such as methane, ethanol, carbon monoxide and ammonia. NiO/ $\mathrm{Fe}_{2} \mathrm{O}_{3}$ composites have been reported to show great sensitivity towards toluene, in relation to other gases such as ethanol, propanol, acetone and THF [19]. Similar results were found when co-doping $\mathrm{NiO}$ with $\mathrm{Li}$ and $\mathrm{Ti}$, where the sensor provided a clear advantage for the detection of toluene and not towards other gases [64].

\subsection{Sensor exposure to carbon monoxide}

The sensors were also exposed to carbon monoxide, at concentrations that ranged between 50 and $500 \mathrm{ppm}$ and also at various temperatures $\left(300-500^{\circ} \mathrm{C}\right)$. However, the sensors were almost unresponsive to these test concentrations and this was true across the temperatures investigated. This can be observed in more detail in Fig. 12. Similar results were reported by $[74,75]$ upon exposure to $\mathrm{CO}$ concentrations $<500 \mathrm{ppm}$ with a $\mathrm{NiFe}_{2} \mathrm{O}_{4}$ sensor. The sensor responses increased slightly when supplied with $\mathrm{CO}$ concentrations that exceeded 1000 ppm [74] but their sensor was unable to differentiate between CO and $\mathrm{CH}_{4}$ gases.

\subsection{Sensor exposure to nitrogen dioxide}

When exposing the sensors to trace concentrations of $\mathrm{NO}_{2}$ (ppb level), the sensors behaved as expected. That is, those originally behaving as n-type increased in resistance in its presence and, those that were originally p-type, showed a decrease in resistance.

The sensors were, for the most part, barely responsive to $\mathrm{NO}_{2}$, with one exception: the nickel ferrite sensor (Fig. 13). Although at $350{ }^{\circ} \mathrm{C}$ the nickel ferrite sensor began to show a response towards $50 \mathrm{ppb} \mathrm{NO}_{2}$, it increased significantly when the operating temperature was dropped down to $300^{\circ} \mathrm{C}$. At concentrations of $200 \mathrm{ppb}$ and above, the response output of sensor N6 appeared noisy. Some researchers have expressed it be due to poor particle connectivity $[76,77]$. Because this behaviour was not seen in previous tests this was, therefore, unlikely and the reasons behind this behaviour will be investigated in future. It can also be observed that the shape of the peak $(500 \mathrm{ppb})$ appeared to decrease in magnitude during the supply of gas, which could be due to a number of surface reactions taking place in the sensor. Different reaction products may then lead to enhancements or reductions in the response of the sensing material, according to its sensitivity to the formed gas.

The enhancement in the response of the N6 (nickel ferrite) sensor towards $500 \mathrm{ppb} \mathrm{NO}_{2}$ (ca. 11-fold), in relation to the commerciallybased $\mathrm{NiO}$ sensor was outstanding. The enhancement was also excellent when compared to the other LJS-based NiO nanoparticle sensors ( $c a$. 11-fold). In this instance, sensor N2 displayed similar behaviour to the other sensors (N1, N3-N5). Other studies that have reported the sensitivity of NiO-based nanoparticles towards $\mathrm{NO}_{2}$ found similar results, in that the materials were poorly sensitive to the gas, even when supplied with $10 \mathrm{ppm}[75,78]$. 


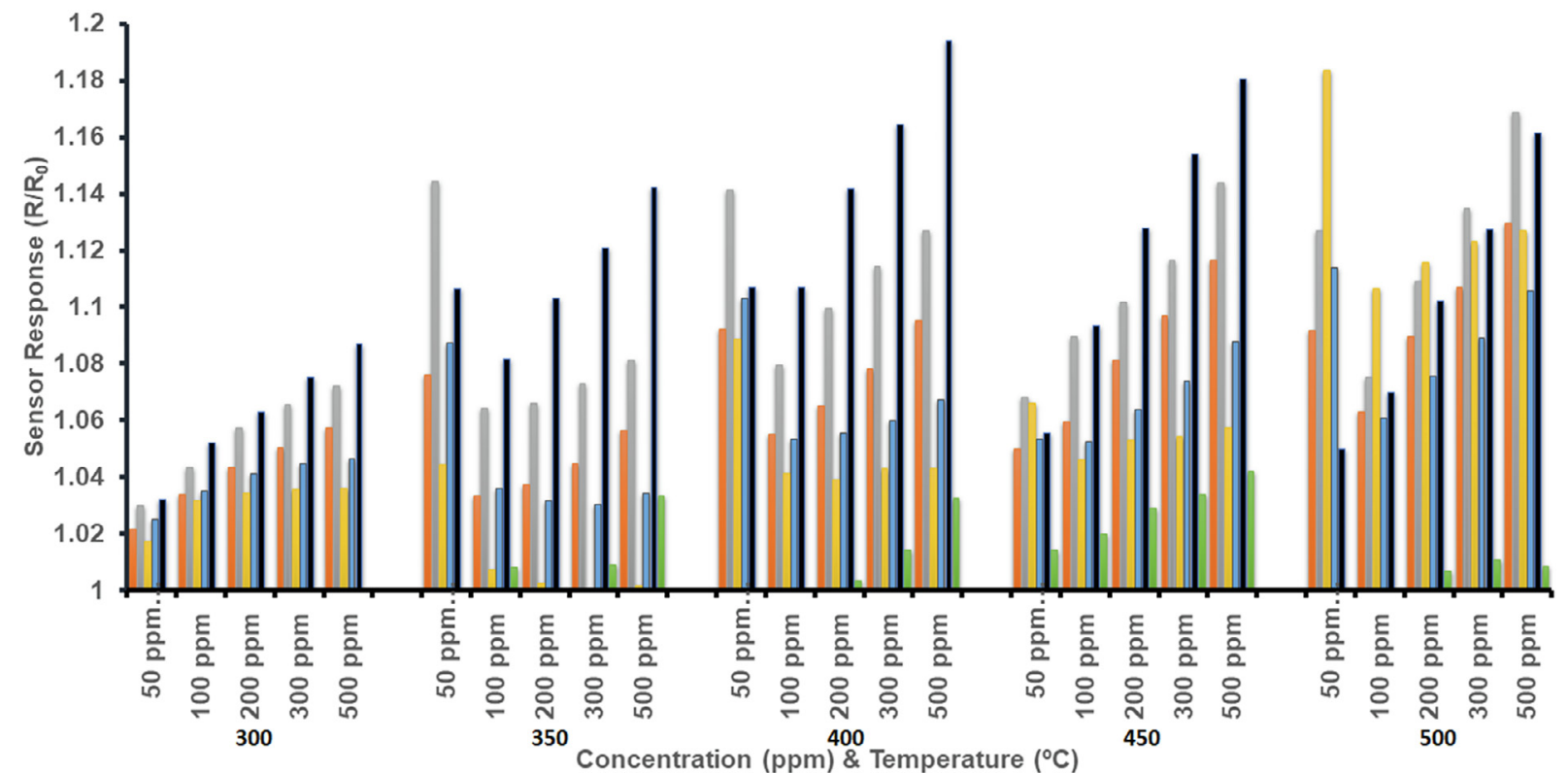

Fig. 12. Sensor responses to a range of carbon monoxide concentrations and temperatures. Note that N6 behaved as an n-type semiconductor and its response was thus calculated as $R_{0} / R$.

\section{Summary and outlook}

Although a few studies have, indeed, evaluated the gas sensing properties of $\mathrm{NiFe}_{2} \mathrm{O}_{4},[73,79-80]$, a very limited number of gases have been previously evaluated and poor sensitivity and selectivity of the sensors has typically been reported $[4,81]$. Generally speaking, the nickel ferrite sensors are commonly found to be selective towards a particular gas, but the gas concentrations investigated have commonly been very high [4,82-83], and far in excess of what can reasonably be expected in real-world investigations of environmental pollutants [3].
Conversely, the nickel ferrite gas sensor prepared here provided excellent sensor performance when exposed to trace gas concentrations and it responded very differently to all the gases that were investigated which, in turn, makes it a good candidate as a selective sensor in future investigations.

The LJS method employed here to synthesise nanoparticle materials offers very attractive advantages over other synthesis methods, such as enabling particle size and shape control and not requiring additional surfactants or capping agents which, consequently, reduces the number of precursors needed for fabrication and facilitates large-scale

\section{Exposure to Nitrogen Dioxide at $300^{\circ} \mathrm{C}$}
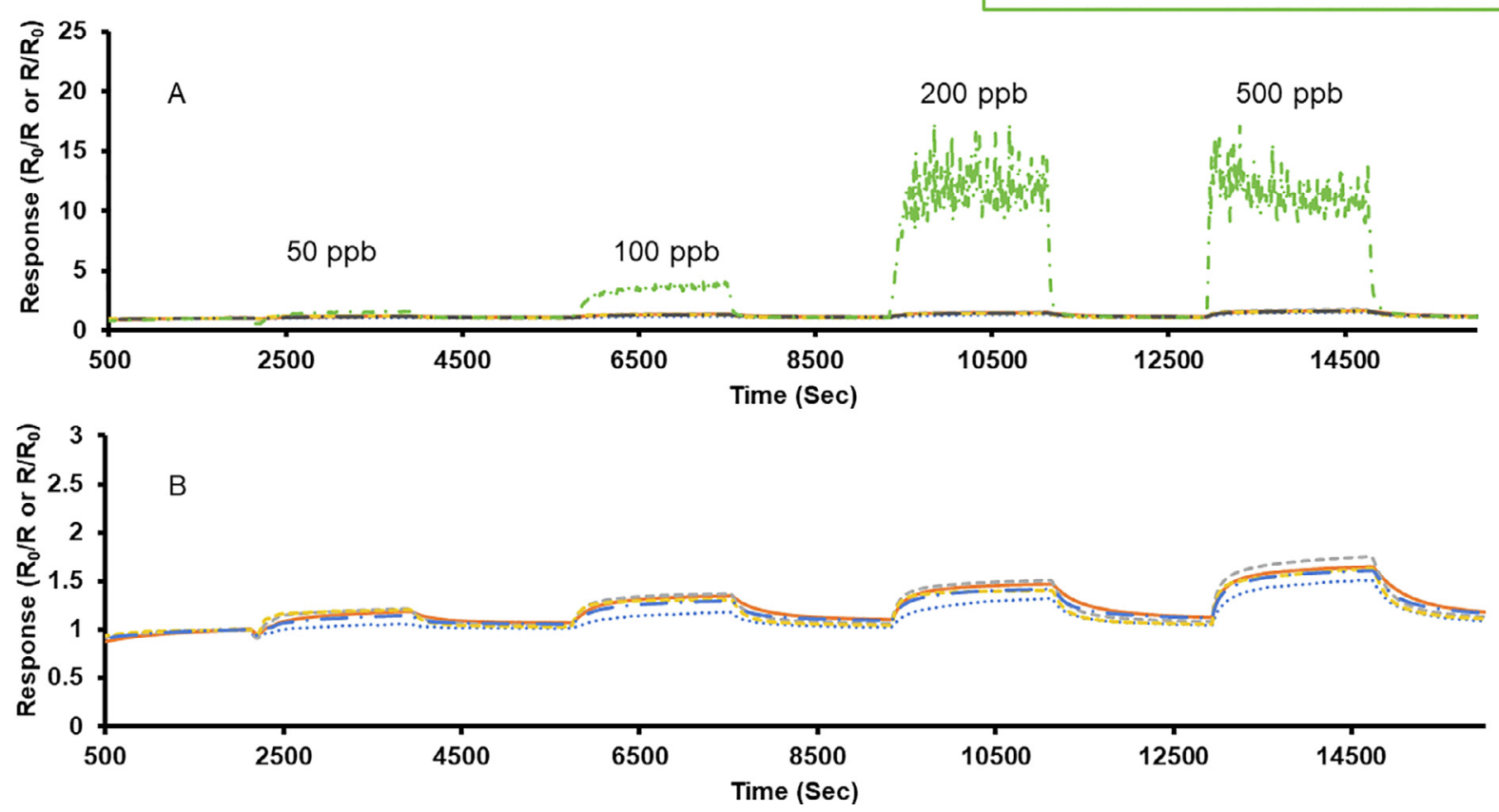

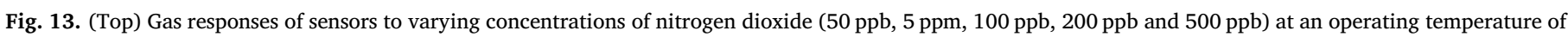

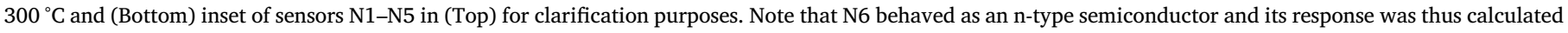
as $R_{0} / R$. 
production of highly pure materials.

It is worth noting that the sensing performance of the LJS nickel ferrite sensor was far better than the other LJS NiO nanoparticle-based sensors prepared in this study and also in relation to that of the $\mathrm{NiO}$ sensor prepared using a commercial powder. Sensor N1 and N2 also showed promise for future gas sensing investigations. Although sensors $\mathrm{N} 1$ and N2 were both responsive to gases such as ethanol and acetone, the former displayed particle morphologies that were oval in shape, whereas the latter had a higher surface area and particle morphologies that were square in appearance. Conversely, it was interesting to see that although sensors N2 and N3 had similar microstructures and particle morphologies, they responded rather differently to the test gases. This may be the result of the different synthesis conditions used to fabricate the materials and/or the result of the materials sintering differently when undergoing heat treatment during the sensor fabrication steps. This may have affected the microstructure of the sensing materials such that the access of the gases through the sensing system was somewhat limited in the N3 sensor microstructure. Further work ought to be carried out in future to investigate this in depth. The sensors were typically more responsive to gases at $350^{\circ} \mathrm{C}$, which is in line with what other groups investigating Ni-based gas sensors have reported in the literature [74].

It has been shown here that modifying the synthesis conditions of the LJS method could lead to different particle properties that worked in favour of gas detection. When the LJS method synthesised particles that were comparable to those of the commercially-sourced $\mathrm{NiO}$ powder, the gas sensing results were very similar among sensors. This study illustrates the value of LJS as an excellent and straightforward means of fabricating nanoparticle materials but, also, as a means of fabricating materials that may be used for the purposes of trace gas detection and with improved sensing performance over commerciallysourced powder materials.

\section{Conclusions}

A levitation-jet synthesis (LJS) method was employed to synthesise a range of nickel-based metal oxide nanoparticles in order to assess their feasibility as gas sensing materials.

The properties of the LJS-based sensors were compared to those of a $\mathrm{NiO}$ sensor fabricated with a commercially-sourced material. The sensing performance of the LJS- fabricated sensors was typically enhanced in relation to that of the sensor fabricated with the commercial $\mathrm{NiO}$ powder. Very interestingly, the $\mathrm{NiFe}_{2} \mathrm{O}_{4}$ gas sensor provided the most responsive sensor outputs to the gases of interest, despite having other sensors in the array that had much-increased surface areas. Furthermore, this sensor alone responded to the gases with different degrees of sensitivity, highlighting its potential as a selective sensor if used as part of a gas sensor array. As a technique, LJS shows great promise for the production of complex oxide materials and it has provided excellent control of the nanoparticle sizes, morphology and phase compositions. This, in turn, has led to the performance of the gas sensors investigated here to be very attractive for future environmental and air-quality applications.

\section{Acknowledgements}

We would like to acknowledge Dr. Russell Binions, Dr. Steve Firth and Dr. Sanjay Sathasivam for help with discussion and analysis.

\section{References}

[1] S. Hu, X. Wang, Ultrathin nanostructures: smaller size with new phenomena, Chem. Soc. Rev. 42 (12) (2013) 5577-5594, https://doi.org/10.1039/C3CS00006K.

[2] X. Wang, J. Zhuang, Q. Peng, Y. Li, A general strategy for nanocrystal synthesis, Nature 437 (2005) 121-124, https://doi.org/10.1038/nature03968.

[3] G.F. Fine, L.M. Cavanagh, A. Afonja, R. Binions, Metal oxide semi-conductor gas sensors in environmental monitoring, Sensors 10 (6) (2010) 5468-5502, https:// doi.org/10.3390/s100605469.

[4] S.L. Darshane, S.S. Suryavanshi, I.S. Mulla, Nanostructured nickel ferrite: a liquid petroleum gas sensor, Ceram. Int. 35 (5) (2009) 1793-1797, https://doi.org/10 1016/j.ceramint.2008.10.013.

[5] A. Afzal, N. Cioffi, L. Sabbatini, L. Torsi, $\mathrm{NO}_{\mathrm{x}}$ sensors based on semiconducting metal oxide nanostructures: progress and perspectives, Sens. Actuators B Chem. 171-172 (1) (2012) 25-42, https://doi.org/10.1016/j.snb.2012.05.026.

[6] D.E. Williams, Semiconducting oxides as gas-sensitive resistors, Sens. Actuators B Chem. 57 (1-3) (1999) 1-16, https://doi.org/10.1016/S0925-4005(99)00133-1.

[7] R. Binions, A. Afonja, S. Dungey, D.E. Lewis, I.P. Parkin, D.E. Williams, Discrimination effects in zeolite modified metal oxide semiconductor gas sensors, IEEE Sens. J. 11 (5) (2011) 1145-1151, https://doi.org/10.1109/JSEN.2010. 2084079.

[8] P.Y. Lee, K. Ishizaka, H. Suematsu, W. Jiang, K. Yatsui, Magnetic and gas sensing property of nanosized $\mathrm{NiFe}_{2} \mathrm{O}_{4}$ powders synthesized by pulsed wire discharge, J. Nanopart. Res. 8 (1) (2006) 29-35, https://doi.org/10.1007/s11051-005-5427-z.

[9] S.W. Oh, H.J. Bang, Y.C. Bae, Y.-K. Sun, Effect of calcination temperature on morphology, crystallinity and electrochemical properties of nano-crystalline metal oxides $\left(\mathrm{Co}_{3} \mathrm{O}_{4}, \mathrm{CuO}\right.$, and $\left.\mathrm{NiO}\right)$ prepared via ultrasonic spray pyrolysis, J. Power Sources 173 (1) (2007) 502-509, https://doi.org/10.1016/j.jpowsour.2007.04. 087.

[10] X. Deng, Z. Chen, Preparation of nano-NiO by ammonia precipitation and reaction in solution and competitive balance, Mater. Lett. 58 (3-4) (2004) 276-280, https:// doi.org/10.1016/S0167-577X(03)00469-5.

[11] U. Ahmad, B.-K. Kim, J.-J. Kim, Y.-B. Hahn, Optical and electrical properties of ZnO nanowires grown on aluminium foil by non-catalytic thermal evaporation, Nanotechnology 18 (17) (2007) 175606, https://doi.org/10.1088/0957-4484/18/ $17 / 175606$.

[12] C.N.P. da Fonseca, M.-A. de Paoli, A. Gorenstein, The electrochromic effect in cobalt oxide thin films, Adv. Mater. 3 (11) (1991) 553-555, https://doi.org/10.1002/ adma.19910031107.

[13] K. Hayat, M.A. Gondal, M.M. Khaled, S. Ahmed, Effect of operational key parameters on photocatalytic degradation of phenol using nano nickel oxide synthesized by sol-gel method, J. Mol. Cat. A Chem. 336 (1-2) (2011) 64-71, https://doi.org/ 10.1016/j.molcata.2010.12.011.

[14] S. Illy-Cherrey, O. Tillement, J.M. Dubois, M. Massicot, Y. Fort, J. Ghanbaja, S. Bégin-Colin, Synthesis and characterization of nano-sized nickel(II), copper(I) and zinc(II) oxide nanoparticles, Mater. Sci. Eng. A 338 (1-2) (2002) 70-75, https://doi.org/10.1016/S0921-5093(02)00057-6.

[15] Y. Wang, Q.-Z. Qin, A nanocrystalline NiO thin-film electrode prepared by pulsed laser ablation for Li-ion batteries, J. Electrochem. Soc. 149 (7) (2002) A873-A878, https://doi.org/10.1149/1.1481715.

[16] G. Zhu, C. Xi, H. Xu, D. Zheng, Y. Liu, X. Xu, X. Shen, Hierarchical NiO hollow microspheres assembled from nanosheet-stacked nanoparticles and their application in a gas sensor, RSC Adv. 2 (10) (2012) 4236-4241, https://doi.org/10.1039/ C2RA01307J.

[17] M. Kooti, L. Matouri, A facile and mild method for synthesis of nickel oxide nanoparticles in the presence of various surfactants, Res. Rev. J. Mater. Sci. 2 (1) (2014) 37-42, https://doi.org/10.4172/2321-6212.1000118.

[18] D. Ju, H. Xu, Q. Xu, H. Gong, Z. Qiu, J. Guo, High triethylamine-sensing properties of $\mathrm{NiO} / \mathrm{SnO}_{2}$ hollow sphere $\mathrm{P}-\mathrm{N}$ heterojunction sensors, Sens. Actuators B Chem. 215 (2015) 39-44, https://doi.org/10.1016/j.snb.2015.03.015.

[19] K. Arshak, I. Gaidan, $\mathrm{NiO} / \mathrm{Fe}_{2} \mathrm{O}_{3}$ polymer thick films as room temperature gas sensors, Thin Solid Films 495 (1-2) (2006) 286-291, https://doi.org/10.1016/j.tsf. 2005.08.298.

[20] S.L. Darshane, S.S. Suryavanshi, I.S. Mulla, Nanostructured nickel ferrite: a liquid petroleum gas sensor, Ceram. Int. 35 (5) (2009) 1793-1797, https://doi.org/10 1016/j.ceramint.2008.10.013.

[21] C.N. Chinnasamy, A. Narayanasamy, N. Ponpandian, K. Chattopadhyay, K. Shinoda, B. Jeyadevan, K. Tohji, K. Nakatsuka, T. Furubayashi, I. Nakatani, Mixed spinel structure in nanocrystalline $\mathrm{NiFe}_{2} \mathrm{O}_{4}$, Phys. Rev. B 63 (18) (2001) 184108, https:// doi.org/10.1103/PhysRevB.63.184108.

[22] A.S. Albuquerque, J.D. Ardisson, W.A.A. Macedo, J.L. López, R. Paniago, A.I.C. Persiano, Structure and magnetic properties of nanostructured Ni-ferrite, J. Magn. Magn. Mater. 226-230 (2) (2001) 1379-1381, https://doi.org/10.1016/ S0304-8853(00)00915-X.

[23] D. Ortega, M.V. Kuznetsov, Yu.G. Morozov, O.V. Belousova, I.P. Parkin, Thermal relaxation and collective dynamics of interacting aerosol-generated hexagonal $\mathrm{NiFe}_{2} \mathrm{O}_{4}$ nanoparticles, PCCP 15 (48) (2013) 20830-20838, https://doi.org/10. 1039/c3cp53981d.

[24] K. Madhusudan Reddy, L. Satyanarayana, V. Manorama, Sunkara, R.D.K. Misra, A comparative study of the gas sensing behavior of nanostructured nickel ferrite synthesized by hydrothermal and reverse micelle techniques, Mater. Res. Bull. 39 (10) (2004) 1491-1498, https://doi.org/10.1016/j.materresbull.2004.04.022.

[25] L. Satyanarayana, K. Madhusudan Reddy, V. Manorama, Sunkara, Nanosized spinel $\mathrm{NiFe}_{2} \mathrm{O}_{4}$ : a novel material for the detection of liquefied petroleum gas in air, Mater. Chem. Phys. 82 (1) (2003) 21-26, https://doi.org/10.1016/S0254-0584(03) 00170-6.

[26] N.-S. Chen, X.-J. Yang, E.-S. Liu, J.-L. Huanget, Reducing gas-sensing properties of ferrite compounds $\mathrm{MFe}_{2} \mathrm{O}_{4}(\mathrm{M}=\mathrm{Cu}, \mathrm{Zn}, \mathrm{Cd}$ and $\mathrm{Mg})$, Sens. Actuators B Chem. 66 (1-3) (2000) 178-180, https://doi.org/10.1016/S0925-4005(00)00368-3.

[27] D.-H. Chen, X.-R. He, Synthesis of nickel ferrite nanoparticles by sol-gel method, Mater. Res. Bull. 36 (7-8) (2001) 1369-1377, https://doi.org/10.1016/S00255408(01)00620-1.

[28] J. Liu, H. He, X. Jin, Z. Hao, Z. Xu, Synthesis of nanosized nickel ferrites by shock waves and their magnetic properties, Mater. Res. Bull. 36 (13-14) (2001) 2357-2363, https://doi.org/10.1016/S0025-5408(01)00722-X.

[29] H. Suematsu, K. Ishizaka, Y. Kinemuchi, T. Suzuki, W. Jiang, K. Yatsui, Novel critical temperature resistor of sintered $\mathrm{Ni}-\mathrm{Fe}-\mathrm{O}$ nanosized powders, J. Mater. Res. 19 (04) (2004) 1011-1014, https://doi.org/10.1557/JMR.2004.0131. 
[30] D. Ortega, M.V. Kuznetsov, Y.G. Morozov, O.V. Belousova, I.P. Parkin, Phase, size and shape controlled formation of aerosol generated nickel and nickel oxide nanoparticles, J. Alloys Compd. 579 (2013) 495-501, https://doi.org/10.1016/j. jallcom.2013.06.128.

[31] Y.G. Morozov, O.V. Belousova, M.V. Kuznetsov, D. Ortega, I.P. Parkin, Electric fieldassisted levitation-jet aerosol synthesis of $\mathrm{Ni} / \mathrm{NiO}$ nanoparticles, J. Mater. Chem. 22 (22) (2012) 11214-11223, https://doi.org/10.1039/c2jm31233f.

[32] Y.G. Morozov, D. Ortega, O.V. Belousova, I.P. Parkin, M.V. Kuznetsov, Some peculiarities in the magnetic behavior of aerosol generated NiO nanoparticles, J. Alloys Compd. 572 (2013) 150-157, https://doi.org/10.1016/j.jallcom.2013.03. 260.

[33] A.P. Krasnov, Yu.G. Morozov, E.A. Chernov, Characteristic features of the vaporization mechanism in the crucible-free production of aerosol particles, Powd. Technol. 81 (1) (1994) 93-98, https://doi.org/10.1016/0032-5910(94)02871-0.

[34] P. Tarttelin Hernández, M.V. Kuznetsov, Yu.G. Morozov, High-temperature synthesis of nickel-based nanoparticles for use as materials in sensors of potentially hazardous gases, Int. J. SHS 28 (3) (2019) (accepted).

[35] R. Binions, H. Davies, A. Afonja, S. Dungey, D. Lewis, D.E. Williams, I.P. Parkin, Zeolite-modified discriminating gas sensors, J. Electrochem. Soc. 156 (3) (2009) J46-J51, https://doi.org/10.1149/1.3065436.

[36] W.J. Peveler, R. Binions, S.M.V. Hailes, I.P. Parkin, Detection of explosive markers using zeolite modified gas sensors, J. Mater. Chem. A 1 (7) (2013) 2613-2620, https://doi.org/10.1039/c2ta01027e.

[37] P. Tarttelin Hernández, A.J.T. Naik, E.J. Newton, S.M.V. Hailes, I.P. Parkin, Assessing the potential of metal oxide semiconducting gas sensors for illicit drug detection markers, J. Mater. Chem. A 2 (23) (2014) 8952-8960, https://doi.org/10. 1039/c4ta00357h.

[38] Hernández P. Tarttelin, Modification of n-type and p-type Metal Oxide Semiconductor Systems for Gas Sensing Applications, $\mathrm{PhD}$ thesis, University College London, London, 2017.

[39] A.C.F.M. Costa, R.T. Lula, R.H.G.A. Kiminami, L.F.V. Gama, A.A. de Jesus, H.M.C. Andrade, Preparation of nanostructured $\mathrm{NiFe}_{2} \mathrm{O}_{4}$ catalysts by combustion reaction, J. Mater. Sci. 41 (2006) 4871-4875, https://doi.org/10.1007/s10853006-0048-1.

[40] N. Mironova-Ulmane, A. Kuzmin, I. Sildos, M. Pärs, Polarisation dependent Raman study of single-crystal nickel oxide, Cent. Eur. J. Phys. 9 (4) (2011) 1096-1099, https://doi.org/10.2478/s11534-010-0130-9.

[41] M. Tadic, M. Panjan, D. Markovic, B. Stanojevic, D. Jovanovic, I. Milosevic, V. Spasojevic, NiO core-shell nanostructure with ferromagnetic-like behavior at room temperature, J. Alloys Compd. 586 (Supplement 1) (2014) S322-S325, https://doi.org/10.1016/j.jallcom.2012.10.166.

[42] G. Anandha Babu, G. Ravi, M. Navaneethan, M. Arivanandhan, Y. Hayakawa, An investigation of flower shaped $\mathrm{NiO}$ nanostructures by microwave and hydrothermal route, J. Mater. Sci. Mater. Electron. 25 (12) (2014) 5231-5240, https://doi.org/ 10.1007/s10854-014-2293-4.

[43] E.L. Simmons, Diffuse reflectance spectroscopy: a comparison of the theories, Appl. Opt. 14 (6) (1975) 1380-1386, https://doi.org/10.1364/AO.14.001380.

[44] S. Rehman, A. Mumtaz, S.K. Hasanain, Size effects on the magnetic and optical properties of $\mathrm{CuO}$ nanoparticles, J. Nanopart. Res. 13 (6) (2011) 2497-2507, https://doi.org/10.1007/s11051-010-0143-8.

[45] H. Lin, C.P. Huang, W. Li, S. Ismat Shah, Y.-H. Tseng, Size dependency of nanocrystalline $\mathrm{TiO}_{2}$ on its optical property and photocatalytic reactivity exemplified by 2-chlorophenol, Appl. Catal. B Environ. 68 (1-2) (2006) 1-11, https://doi.org/10. 1016/j.apcatb.2006.07.018.

[46] J. Tauc, Optical properties and electronic structure of amorphous $\mathrm{Ge}$ and $\mathrm{Si}$, Mater. Res. Bull. 3 (1) (1968) 37-46, https://doi.org/10.1016/j.ssc.2006.01.031.

[47] X. Li, Z. Zhang, Y. Qian Li, Synthesis and characteristics of NiO nanoparticles by thermal decomposition of nickel dimethylglyoximate rods, Solid State Commun. 137 (11) (2006) 581-584, https://doi.org/10.1103/PhysRevB.2.3112.

[48] G. Madhu, V., Biju Nanostructured amorphous nickel oxide with enhanced antioxidant activity, J. Alloys Compd. 637 (2015) 62-69, https://doi.org/10.1016/j. jallcom.2015.02.157.

[49] D. Adler, J. Feinleib, Electrical and optical properties of narrow-band materials, Phys. Rev. B 2 (8) (1970) 3112-3134, https://doi.org/10.1103/PhysRevB.2.3112.

[50] V. Biju, Ni 2p X-ray photoelectron spectroscopy study of nanostructured nickel oxide, Mater. Res. Bull. 42 (5) (2007) 791-796, https://doi.org/10.1016/j. materresbull.2006.10.009.

[51] A.P. Grosvenor, M.C. Biesinger, R.St.C. Smart, N.S. McIntyre, New interpretations of XPS spectra of nickel metal and oxides, Surf. Sci. 600 (9) (2006) 1771-1779, https://doi.org/10.1016/j.susc.2006.01.041.

[52] E. Comini, C. Baratto, G. Faglia, M. Ferroni, A. Vomiero, G. Sberveglieri, Quasi-one dimensional metal oxide semiconductors: preparation, characterization and application as chemical sensors, Prog. Mater. Sci. 54 (2009) 1-67, https://doi.org/10. 1016/j.pmatsci.2008.06.003.

[53] R. Ciprian, P. Torelli, A. Giglia, B. Gobaut, B. Ressel, G. Vinai, M. Stupar, A. Caretta, G. De Ninno, T. Pincelli, B. Casarin, G. Adhikary, G. Sberveglieri, C. Baratto, M. Malvestuto, New strategy for magnetic gas sensing, RSC Adv. 6 (2016) 83399-83405, https://doi.org/10.1039/C6RA18213E.

[54] D. Matatagui, O.V. Kolokoltsev, N. Qureshi, E.V. Mejíla-Uriarte, J.M. Saniger, A magnonic gas sensor based on magnetic nanoparticles, Nanoscale 7 (2015) 9607-9613, https://doi.org/10.1039/C5NR01499A.

[55] A. Punnose, K.M. Reddy, A. Thurber, J. Hays, M. Enhelhard, Novel magnetic hydrogen sensing: A case study using antiferromagnetic haematite nanoparticles, Nanotechnology 18 (2007) 165502, https://doi.org/10.1088/0957-4484/18/16/ 165502.
[56] Y.G. Morozov, D. Ortega, O.V. Belousova, I.P. Parkin, M.V. Kuznetsov, Some peculiarities in the magnetic behavior of aerosol generated $\mathrm{NiO}$ nanoparticles, J. Alloys Compd. 572 (2013) 150-157, https://doi.org/10.1016/j.jallcom.2013.03. 260.

[57] R. Jaaniso, O. Kian Tan (Eds.), Semiconductor Gas Sensors, 1st ed., Woodhead Publishing, Oxford, 2013, p. 562.

[58] A. Gurlo, R. Riedel, In situ and operando spectroscopy for assessing mechanisms of gas sensing, Angew. Chem. - Intern. Ed. 46 (21) (2007) 3826-3848.

[59] A. Gurlo, Interplay between $\mathrm{O} 2$ and $\mathrm{SnO} 2$ : oxygen ionosorption and spectroscopic evidence for adsorbed oxygen, ChemPhysChem 7 (10) (2006) 2041-2052.

[60] A. Gurlo, N. Bârsan, A. Oprea, M. Sahm, T. Sahm, U. Weimar, An n- to p-type conductivity transition induced by oxygen adsorption on $\alpha-\mathrm{Fe}_{2} \mathrm{O}_{3}$, Appl. Phys. Lett 85 (12) (2004) 2280, https://doi.org/10.1063/1.1794853.

[61] A. Gurlo, M. Sahm, A. Oprea, N. Bârsan, U. Weimar, A p- to n-transition on $\alpha-\mathrm{Fe}_{2} \mathrm{O}_{3}$ based thick film sensors studied by conductance and work function change measurements, Sens. Actuators B Chem. 102 (2) (2004) 291-298, https://doi.org/10. 1016/j.snb.2004.04.075.

[62] S. Pati, A. Maity, P. Banerji, S.B. Majumder, Temperature dependent donor-acceptor transition of $\mathrm{ZnO}$ thin film gas sensor during butane detection, Sens. Actuators B Chem. 183 (2013) 172-178, https://doi.org/10.1016/j.snb.2013.03.120.

[63] P. Tarttelin Hernández, S.M.V. Hailes, I.P. Parkin, Hydrocarbon detection with metal oxide semiconducting gas sensors modified by overlayer or admixture of zeolites Na-A, H-Y and H-ZSM-5, Sens. Actuators B Chem. 242 (2017) 1281-1295, https://doi.org/10.1016/j.snb.2016.09.006.

[64] A. Sutka, A. Gross, Spinel ferrite oxide semiconductor gas sensors, Sens. Actuators B Chem. 222 (2016) 95-105, https://doi.org/10.1016/j.snb.2015.08.027.

[65] A. Qureshi, A. Mergen, A. Altindal, Preparation and characterization of Li and Ti codoped NiO nanocomposites for gas sensors applications, Sens. Actuators B Chem. 135 (2009) 537-540, https://doi.org/10.1016/j.snb.2008.09.029.

[66] T. Sathiwitayakul, E. Newton, I.P. Parkin, M. Kuznetsov, R. Binions, Ferrite Materials Produced from self-propagating high-temperature synthesis for gas sensing applications, IEEE Sens. J. 15 (1) (2015) 196-200, https://doi.org/10.1109/ JSEN.2014.2337354.

[67] T. Sathitwitayakul, M.V. Kuznetsov, I.P. Parkin, R. Binions, The gas sensing properties of some complex metal oxides prepared by self-propagating high-temperature synthesis, Mater. Lett. 75 (2012) 36-38, https://doi.org/10.1016/j.matlet.2012.02. 003.

[68] X. Deng, L. Zhang, J. Guo, Q. Chen, J. Ma, ZnO enhanced NiO-based gas sensors towards ethanol, Mater. Res. Bull. 90 (2017) 170-174, https://doi.org/10.1016/j. materresbull.2017.02.040.

[69] S. Ahlers, G. Müller, T. Doll, A rate equation approach to the gas sensitivity of thin film metal oxide materials, Sens. Actuators B Chem. 107 (2) (2005) 587-599, https://doi.org/10.1016/j.snb.2004.11.020.

[70] S. Ahlers, G. Müller, T. Doll, Factors Influencing the Gas Sensitivity of Metal Oxide Materials. in: C.A. Grimes, E.C. Dickey, M.V. Pishko (Eds.), Encylcopedia of Sensors, vol. 10, American Scientific Publishers, 2006.

[71] N. Rezlescu, N. Iftimie, E. Rezlescu, C. Doroftei, P.D. Popa, Semiconducting gas sensor for acetone based on the fine grained nickel ferrite, Sens. Actuators B Chem 114 (1) (2006) 427-432, https://doi.org/10.1016/j.snb.2005.05.030.

[72] H.-J. Kim, J.-H. Lee, Highly sensitive and selective gas sensors using p-type oxide semiconductors: overview, Sens. Actuators B Chem. 192 (2014) 607-627, https:// doi.org/10.1016/j.snb.2013.11.005.

[73] C. Wang, X. Cheng, X. Zhou, P. Sun, X. Hu, K. Shimanoe, N. Yamazoe, Hierarchical $\alpha-\mathrm{Fe}_{2} \mathrm{O}_{3} / \mathrm{NiO}$ composites with a hollow structure for a gas sensor, ACS Appl. Mater. Interfaces 6 (15) (2014) 12031, https://doi.org/10.1021/am501063z.

[74] L. Yang, Y. Xie, H. Zhao, X. Wu, Y. Wang, Preparation and gas-sensing properties of $\mathrm{NiFe}_{2} \mathrm{O}_{4}$ semiconductor materials, Solid State Electron. 49 (6) (2005) 1029-1033, https://doi.org/10.1016/j.sse.2005.03.022.

[75] J. Choi, J. Byun, S. Sub, Chemical Influence of grain size on gas-sensing properties of chemiresistive p-type NiO nanofibers, Sens. Actuators B Chem. 227 (2016) 149-156, https://doi.org/10.1016/j.snb.2015.12.014.

[76] A. Afonja, Use of Zeolites to Effect Discrimination in Metal Oxide Semiconductor Gas Sensors, University College London, 2012.

[77] A.J.T. Naik, Hetero-junction and Nanomaterial Systems for Metal Oxide Semiconductor Based Gas Sensing, University College London, 2014.

[78] V. Kruefu, A. Wisitsoraat, D. Phokharatkul, A. Tuantranont, S. Phanichphant, Chemical Enhancement of p-type gas-sensing performances of $\mathrm{NiO}$ nanoparticles prepared by precipitation with $\mathrm{RuO}_{2}$ impregnation, Sens. Actuators B Chem. 236 (2) (2016) 466-473, https://doi.org/10.1016/j.snb.2016.06.028.

[79] A.B. Gadkari, T.J. Shinde, P.N. Vasambekar, Ferrite gas sensors, IEEE Sens. J. 11 (4) (2011) 849-861, https://doi.org/10.1109/JSEN.2010.2068285.

[80] X. Chu, S. Zhou, W. Zhang, H. Shui, Trimethylamine sensing properties of nano$\mathrm{LaFeO}_{3}$ prepared using solid state reaction in the presence of PEG400, Mater. Sci. Eng., B 164 (1) (2009) 65-69, https://doi.org/10.1016/j.mseb.2009.06.014.

[81] C. Xiangfeng, J. Dongli, Z. Chenmou, The preparation and gas-sensing properties of $\mathrm{NiFe}_{2} \mathrm{O}_{4}$ nanocubes and nanorods, Sens. Actuators B Chem. 123 (2) (2007) 793-797, https://doi.org/10.1016/j.snb.2006.10.020.

[82] C. Feng, S. Ruan, J. Li, B. Zou, J. Luo, W. Chen, W. Dong, F. Wu, Ethanol sensing properties of $\mathrm{LaCo}_{\mathrm{x}} \mathrm{Fe}_{1-\mathrm{x}} \mathrm{O}_{3}$ nanoparticles: effects of calcination temperature, codoping and carbon nanotube treatment, Sens. Actuators B Chem. 155 (1) (2011) 232-238, https://doi.org/10.1016/j.snb.2010.11.053.

[83] Y. Zhang, W. Zeng, New insight into gas sensing performance of nanoneedle-assembled and nanosheet-assembled hierarchical NiO nanoflowers, Mater. Lett. 195 (C) (2017) 217-219, https://doi.org/10.1016/j.matlet.2017.02.124. 